\title{
Zwei „unerhörte Exempel“ Die Kapitulationen von Pirna 1756 und Maxen 1759 im Vergleich
}

\author{
von \\ MARCUS VON SALISCH
}

Am 16. Oktober 1756, nachdem die kursächsische Armee bereits etwa sechs Wochen bei Pirna von den preußischen Truppen belagert wurde, trat ihr Oberkommandierender, Feldmarschall Graf von Rutowski, in aussichtsloser Lage in Verhandlungen mit dem preußischen König. Seinem Kurfürsten Friedrich August II. erklärte er: Die Armee hat der Ehre genügt! und streckte mit dem sächsischen Heer die Waffen. Der Hofstaat reiste nach Warschau ab und Rutowski blieb während des Krieges Oberkommandierender einer de facto nicht mehr existenten Armee. ${ }^{1}$

Etwa drei Jahre später, am 20. November des Kriegsjahres 1759, führten rund 14.000 Preußen unter dem Kommando des Generalfeldmarschalls Friedrich August von Fink auf den verschneiten Höhen bei Maxen einen verzweifelten Kampf mit überlegenen österreichischen Kräften unter dem Kommando des Feldmarschalls Daun. Nach einem nächtlichen Kriegsrat suchte Fink beim Gegner um Waffenstreckung an. Noch am folgenden Vormittag legten die preußischen Soldaten ihre Waffen nieder. Fink kommentierte später: Soviele Leuthe aber aufzuopfern, obne dem Könige nur den geringsten Dienst dadurch zu erzeigen,

1 Zur Kapitulation des sächsischen Heeres bei Pirna und zur kursächsischen Armee im Siebenjährigen Krieg exemplarisch: Marcus von SAlisch, Treue Deserteure. Das kursächsische Militär und der Siebenjährige Krieg, München 2009; Stefan Kroll, Soldaten im 18. Jahrhundert zwischen Friedensalltag und Kriegserfahrung. Lebenswelten und Kultur in der kursächsischen Armee 1728-1796 (Krieg in der Geschichte 26), Paderborn 2006; Ludolf Pelizaeus, Prinz Xaver als Soldat und Militärreformer, in: Uwe Fiedler/Thomas Nicklas/Hendrik Thoß (Hg.), Die Gesellschaft des Fürsten. Prinz Xaver von Sachsen und seine Zeit, Chemnitz 2009, S. 61-69; Christopher Dufry, Friedrich der Große. Die Biographie, Düsseldorf 2001, S. 147-160; Dietmar Bode, 1756. Der Beginn des Siebenjährigen Krieges in Sachsen (Schriften des Arbeitskreises Sächsische Militärgeschichte 5); Horst HöHNE, Die Einstellung der sächsischen Regimenter in die preußische Armee im Jahre 1756 (Hallische Forschungen zur neueren Geschichte, Neue Folge 1), Halle 1926; Der Siebenjährige Krieg 1756-1763. Pirna und Lobositz (Die Kriege Friedrichs des Großen 3/1), hrsg. vom Großen Generalstab, Kriegsgeschichtliche Abteilung II, Bad Honnef 1982 (Neudruck der Ausgabe Berlin 1901); Oskar Schuster/Friedrich A. Francke, Geschichte der Sächsischen Armee von deren Errichtung bis auf die neueste Zeit, 2. Teil, Leipzig 1885; HeInrich A. Aster, Beleuchtung der Kriegswirren zwischen Preußen und Sachsen von Ende August bis Ende Oktober 1756. Mit einem Rückblick auf Zustand, Geist und Bildung beider Armeen, Dresden 1848; Oтto Grosse, Prinz Xaver von Sachsen und das sächsische Korps bei der französischen Armee 1758-1763, Leipzig 1907. 
dieses hätte ich wohl vor Gott, dem Könige selbst und der gantzen Welt nicht verantworten können. Seinem König stieg indessen die Glut ins Gesicht ${ }^{2}$ und er notierte: Es ist bis dato ein gantz unerbörtes Exempel, daß ein preußisches Corps das Gewehr vor seinem Feinde niedergeleget, von dergleichen Vorfall man vorhin gar keine Idee gebabt. ${ }^{3}$

Pirna und Maxen - zwei Kapitulationen mit großer Nachwirkung: in politischer, militärischer und auch in mentaler Hinsicht. Die näher zu untersuchenden Ereignisse waren nicht nur eingebettet in ein und denselben Konflikt - den Siebenjährigen Krieg 1756 bis 1763, dessen Ereignisse sich derzeit zum 250. Male gejährt haben -, sie entstammen zudem derselben Kategorie von militärhistorischen Phänomenen. Damit können sie als grundsätzlich geeignet befunden werden für

2 So zumindest die Überlieferung durch seinen Vorleser; Willy Schüssler (Hg.), Friedrich der Große. Gespräche mit Catt, Leipzig 1940, S. 391-398.

3 Zitiert nach Artur Brabant, Kesselsdorf und Maxen, Zwei Winterschlachten bei Dresden (Deutsche Schlachtfelder 1), Dresden 1912, S. 204 f. Zum Gefecht bei Maxen weiterhin exemplarisch: Werner Netzschwitz, Die Schlacht bei Maxen am 20. November 1759, Maxen 2004; Duffy, Friedrich (wie Anm. 1), S. 277-282; Dennis E. Showalter, The Wars of Frederick the Great, London 1997, S. 250-259; Wolfgang LотZ, Kriegsgerichtsprozesse des Siebenjährigen Krieges in Preußen. Untersuchungen zur Beurteilung militärischer Leistungen durch Friedrich II., Frankfurt a. M. 1981, S. 93-117; Ludwig Mollwo, Die Kapitulation bei Maxen, Marburg 1893 (mit Diskussion der Sichtweisen u. a. Gaudis, Tempelhoffs und Friedrichs II.); siehe auch die Besprechungen dazu von Hans Delbrück, in: Preussische Jahrbücher 7 (1893), S. 150 und Max Immich, in: Forschungen zur Brandenburgischen und Preussischen Geschichte 6/2 (1893), S. 285 f.; Kurt Treutzsch vom Buttlar, Zur Kapitulation von Maxen, in: Forschungen zur Brandenburgischen und Preussischen Geschichte 7 (1894), S. 217-220; Georg Winter, Die kriegsgeschichtliche Überlieferung über Friedrich den Großen kritisch geprüft an dem Beispiel der Kapitulation von Maxen (Historische Untersuchungen 7), Berlin 1888; Der Siebenjährige Krieg 1756-1763. Minden und Maxen (Die Kriege Friedrichs des Großen 3/11), hrsg. vom Großen Generalstab, Kriegsgeschichtliche Abteilung II, Berlin 1912; Artur Brabant, Der Kampf um Kursachsen 1759 (Das Heilige Römische Reich teutscher Nation im Kampfe mit Friedrich dem Großen 3), Dresden 1931; Gr. L., Ein Rückblick auf General von Fink, den Capitulanten bei Maxen 1759, in: Zeitschrift für Preußische Geschichte und Landeskunde 13 (1876), S. 223-237; Bericht von demjenigen, welches man dem General-Lieutenant von Fink wegen der unglücklichen Action bey Maxen hat zur Last legen wollen, und dessen Verantwortung hierüber, nebst denen beygefügten Copien dererjenigen Ordres, welche der General-Lieutenant Fink vor der Action vom Könige erhalten hat; welchem allen noch eine authentische Relation von dieser unglücklichen Action beygefügt ist, in: Zeitschrift für Kunst, Wissenschaft und Geschichte des Krieges 81 (1851), S. 193-231; E. V. Dietrich, Der Finkenfang bei Maxen im November 1759. Ein Schlachtengemälde aus dem Siebenjährigen Krieg, Prag 1846; Johann Gottlieb Tielke, Das Treffen bey Maxen, nebst einer Abhandlung von dem Angriff und Vertheidigung unverschanzter Anhöhen und Berge, mit Plans (Beyträge zur Geschichte der Kriegs-Kunst und Geschichte des Krieges von 1756. bis 1763., I. Stück), Freyberg 1776. Zum Werk des sächsischen Hauptmannes Tielke urteilt Mollwo: „Von allen Darstellungen aus dem vorigen Jahrhundert über die Kapitulation ist es eine einzige, welche wirklich selbständige und zuverlässige Nachrichten bietet.“ Er charakterisiert den Zeitzeugen und Militärschriftsteller Tielke als „sehr ruhigen, objektiven, scharfblickenden und zuverlässigen Menschen“; Mollwo, Die Kapitulation (wie Anm. 3), S. 34 f. 
die historiografische Methode des Vergleichens. Hiermit sind aber noch keine Aussagen zu ihrer jeweiligen Gestalt getroffen, denn ein Vergleich soll nicht nur Ähnlichkeiten aufzeigen. In die komparative Betrachtung beider Kapitulationen sollen folgende Aspekte einfließen: Einmal die Vorgeschichte, die zur Einschließung der sächsischen und preußischen Truppen im Kriegsjahr 1756 beziehungsweise 1759 führte. In diesem Zusammenhang wird zumindest schlaglichtartig ebenso auf die „Führungskultur“ in beiden Armeen einzugehen sein, wie auf die Möglichkeiten und Grenzen der maßgeblichen militärischen Führer und deren Persönlichkeiten. Im Folgenden soll die Lage der eingeschlossenen Soldaten beleuchtet werden, bevor der Ablauf der Kapitulation in den Blick genommen wird. Hier wird besonders nach einer spezifischen „Kapitulationskultur“ zu fragen sein, nach möglichen Parallelen im Zeremoniell der Waffenstreckung. Abschließend soll auch das Schicksal der Unterlegenen Beachtung finden, wobei zu trennen sein wird zwischen den Angehörigen der einzelnen Dienstgradgruppen.

\section{Die Vorgeschichte}

Zunächst ist zu betonen, dass die Ereignisse von 1756 beziehungsweise 1759 in unterschiedlichen Stadien des Siebenjährigen Krieges stattfanden. Aufgrund der Formverwandlung erwies sich dieser Konflikt als ein Idealtypus der Clausewitzschen Metapher vom Krieg als „wahres Chamäleon“:4 Von großen, durchgeplanten Schlachten über blutige Gemetzel bis hin zum asymmetrischen Scharmützelkrieg, der vor allem die Endphase bestimmte.

Durch den Überfall auf Sachsen im Jahre 1756 wurde die bereits in Übersee existierende Auseinandersetzung nach Europa getragen. Um der Festigung der Koalition der Gegner Preußens zuvorzukommen, spielte Friedrich II. (1712-1786) ungeduldig das in der historischen Forschung umstrittene „Praevenire“. Zumindest dieser erste Feldzug war durchgeplant, die Ziele klar definiert und der preußische König besaß die Initiative. ${ }^{5}$ Sein Operationsplan sah zumindest vor, rasch

4 Carl von Clausewitz, Vom Kriege, München 2000 (Neudruck der Ausgabe Berlin 1832), S. 46. Zum "chamäleonhaften Charakter" des Krieges siehe auch: AndREAS Herberg-Rothe, Der Krieg. Geschichte und Gegenwart, Frankfurt a. M. 2003, S. 7-23; Michael Salewski, 1756 und die Folgen. Einleitung, in: Historische Mitteilungen der Ranke-Gesellschaft 18 (2005), S. 3.

5 Zum Renversement des alliances, zur Ausgangslage 1756 sowie zum Streit über den Ursprung des Siebenjährigen Krieges exemplarisch: Johannes Kunisch, Friedrich der Große. Der König und seine Zeit, München 2004, S. 330-353, 358 f., 438-441; SveN EXTERNBRINK, Friedrich der Große, Maria Theresia und das Alte Reich. Deutschlandbild und Diplomatie Frankreichs im Siebenjährigen Krieg, Berlin 2006, S. 120 f., 172-186; Angela Kulenkampff, Österreich und das Alte Reich. Die Reichspolitik des Staatskanzlers Kaunitz unter Maria Theresia und Joseph II., Köln 2005, S. 42-44; EcKHARD Buddruss, Die französische Deutschlandpolitik 1756-1789 (Veröffentlichungen des Instituts für europäische Geschichte, Abt. Universalgeschichte 157), Mainz 1995, S. 70-99; Jürgen LuH, Zur Strategie Friedrichs des Großen im Siebenjährigen Krieg, in: 
nach Sachsen einzufallen und die sächsische Armee möglichst noch in ihren Garnisonen gefangen zu nehmen. Die Übergänge nach Böhmen sollten besetzt werden, um eine wirtschaftlich ertragreiche Operationsbasis sowie eine günstige Ausgangsposition für einen eventuellen Feldzug im Jahre $1757 \mathrm{zu}$ besitzen. ${ }^{6}$ Für die sächsische Armee stellte das preußische Heer eine Art „Angstgegner" dar, denn die Erinnerungen an das Aufeinandertreffen in den ersten beiden Schlesischen Kriegen waren vor allem durch Niederlagen geprägt - ein in mentaler Hinsicht sicher nicht unbedeutender Aspekt!

Drei Jahre später, im November 1759, lagen die Dinge anders: Spätestens seit dem Winter 1758/59 war von preußischer Seite aufgrund der enormen Verluste an eine Fortsetzung der offensiven Operationsführung nicht mehr zu denken. Der Abwehrkampf auf der inneren Linie hatte begonnen, der einem Zermürbungskrieg gleichkam.7 Das Gesicht des Krieges hatte sich, wie erwähnt, stark gewandelt. Gut ausgebildete Soldaten - noch dazu „Landeskinder“ - waren in den Regimentern Mangelware, ${ }^{8}$ durchgeplante Schlachten und Feldzüge gehörten der Vergangenheit an, die Zeit der Abnutzungsschlachten war angebrochen. Die Gefechte bei Zorndorf 1758 und Kunersdorf 1759 wurden dafür zum Synonym. Die traumatischen Erfahrungen der preußischen Soldaten aus beiden Gefechten werden sicher nicht ohne psychologische Nachwirkungen auf deren Verhalten bei Maxen gewesen sein.

Zudem müssen Strategie und Taktik im Grundsatz betrachtet werden: Bei Pirna verschanzte sich eine ganze Armee über mehrere Wochen, mit deren Existenz und Durchhaltefähigkeit auch das Schicksal Kursachsens eng verknüpft war. Auch befand sich der sächsische Kurfürst mitsamt seinem Premierminister beim Heer, was zusätzliche Rücksichten erforderte. Bei Maxen wurde binnen Kurzem ein Korps angegriffen und zur Kapitulation gezwungen, welches ausgesandt worden war, vor allem den sogenannten Kleinkrieg zu führen, also die österreichischen Truppen auf ihrem als sicher angenommenen Rückzuge nach Böhmen zu beunruhigen. Maxen war - darauf deutet auch die Abwesenheit des Königs und Feldherrn hin - somit eher ein „Nebenkriegsschauplatz“; die Entsendung Finks war eingebettet in eine größere Gesamtoperation der preußischen Armee.

Militärgeschichte. Zeitschrift für historische Bildung 1 (2006), S. 18-21; MichaEL SALEWSKI, „Praevenire quam praeveniri“. Zur Idee des Präventivkrieges in der späten Neuzeit, in: Historische Mitteilungen der Ranke-Gesellschaft 18 (2005), S. 89-100.

6 Von Salisch, Treue Deserteure (wie Anm. 1), S. 56 f., 66-70; siehe auch das spätere Urteil von Kaunitz über die Besetzung Sachsens bei KunIsch, Friedrich (wie Anm. 5), S. 437.

7 Kunisch, Friedrich (wie Anm. 5), S. 400; Theodor Schieder, Friedrich der Große. Ein Königtum der Widersprüche, Frankfurt a. M. 1983, S. 190.

8 Hinweise auf die regionale Herkunft der Soldaten in den bei Maxen eingesetzten preußischen Regimentern finden sich bei Mollwo, Die Kapitulation (wie Anm. 3), S. 68 f.; Generalstab, Minden und Maxen (wie Anm. 3), S. 203. 
Die ab Juni 1756 beginnenden Rüstungen und Konzentrationen der preuBischen Armeen waren der sächsischen Staats- und Armeeführung nicht verborgen geblieben. Insbesondere Generalfeldmarschall Friedrich August Graf von Rutowski (1702-1764) wies seinen Kurfürsten und Halbbruder Friedrich August II. (1696-1763) auf die drohende Gefahr und den mangelhaften Zustand des kursächsischen Heeres sowie der Festungen und Magazine hin. Es erschien dem Feldmarschall wichtig, wenn alle Corps mobil, beysammen und im Stande wären des vorteilhaften Lauffes des Elb-Strohms sich mittelst einer sichern Defensive zu bedienen. ${ }^{9}$ Im Hinblick auf die strategische Bedeutung der Elbe als Versorgungsweg $^{10}$ für die preußische Operationsführung in Böhmen schlug er eine insgeheim vorbereitete Zusammenziehung bei Pirna vor, da der Posten [...] inattaquable wäre. ${ }^{11}$ Durch die überwiegend von der Zivilbevölkerung geleisteten Schanzarbeiten konnte das Lager mit Feldbefestigungen weiter verstärkt werden. ${ }^{12}$ Besonders hervorzuheben ist zudem die Integration zweier Festungen, des Sonnen- und des Königsteins, in das Verteidigungssystem. Die Schwachstellen des Lagers bei Pirna bestanden, kurz gesagt, einmal in seiner räumlichen Ausdehnung. Die sächsische Armee war zahlenmäßig zu schwach, um im Ernstfall alle Verteidigungswerke angemessen zu besetzen. Wesentliche Nachteile waren außerdem das Fehlen von Ausfallmöglichkeiten für das eingeschlossene Heer und die Tatsache, dass mögliche Rückzugswege nicht durch sächsische Truppen besetzt wurden. Zudem befan-

9 Aus einer Denkschrift Rutowskis vom 8. Juni 1756. Zitiert nach von SALIsch, Treue Deserteure (wie Anm. 1), S. 59 f.; Die Werke der Festung Dresden waren zu dieser Zeit veraltet und litten unter den typischen Belastungen, welche die barocke Fortifikationskunst für eine Stadt mit sich brachte. So war etwa aus Platzmangel die „Brühlsche Terrasse“ auf der Bastion „Venus“ angelegt worden. Zum sächsischen Festungswesen im 18. Jahrhundert im Überblick: Hans-Joachim Kuke, Jean de Bodt 1670-1745. Architekt und Ingenieur im Zeitalter des Barock, Worms 2002, S. 248-251, 254-256; EvA PAPKe, Festung Dresden. Aus der Geschichte einer Stadtbefestigung, Dresden 2007, S. 103-133; Reinhold Müller/Wolfgang Rother, Die kurfürstlich-sächsische Armee um 1791, Berlin 1990, S. 34 f.

10 Wasserwege konnten geradezu das „Rückgrat“ der damaligen Kriegführung bilden. Ein Lastschiff ersetzte aufgrund seiner größeren Transportkapazität zwischen 13 und 26, in Ausnahmefällen sogar bis zu 70 Pferdewagen; Jürgen LuH, Kriegskunst in Europa 1650-1800, Köln 2004, S. 25, 42, 45.

11 In der Tat wurde die Stellung an der Elbe zwischen Pirna, Königstein und Lilienstein nicht nur aus zeitgenössischer Sicht als eine der taktisch stärksten Stellungen Mitteleuropas bezeichnet. Bereits unter August dem Starken wurden Überlegungen zur Verteidigung des Plateaus bei Pirna angestellt. In den von Johann Gottfried von Hoyer 1809 wiedergegebenen Betrachtungen Friedrichs II. wird die Lagerstellung bei Pirna als eine Art von Festung, als eins der stärksten in Europa geschildert; JOHANN GOTTFRIED von Hoyer, Versuch junge Offiziers zum Studium der Kriegsgeschichte aufzumuntern. Mit einem Plan des verschanzten Lagers bey Pirna, Tübingen 1809; Duffy, Friedrich (wie Anm. 1), S. 149; von Salisch, Treue Deserteure (wie Anm. 1), S. 79 f. (mit Karte). Der Bericht eines anonymen Kriegsteilnehmers hierzu ist überliefert in: Tagebuch eines Preußischen Offiziers über die Feldzüge von 1756 bis 1763, in: Sammlung ungedruckter Nachrichten, so die Geschichte der Feldzüge der Preußen von 1740 bis 1779 erläutern, 2. Teil, Bad Honnef 1983 (Neudruck der Ausgabe Dresden 1782-1785), S. 328-352. 
den sich nur sehr wenige Ortschaften und Gewässer im Lager selbst, sodass die Soldaten auf den Proviant und das Futter angewiesen waren, das sie ins Lager mitnahmen..$^{13}$ Trotzdem richteten sich alle Hoffnungen des sächsischen Heeres, welches ab dem 2. September 1756 in Gänze im Lager versammelt war, in der Folgezeit darauf, dass sich Friedrich II. angesichts einer derart starken Verschanzung und der geografischen Hindernisse nicht mit der Belagerung aufhalten und direkt nach Böhmen marschieren würde, um die noch unfertig gerüstete österreichische Armee zu einer vielleicht schon entscheidenden Schlacht zu stellen.

Im Herbst und Winter des „annus horribilis“ 1759 verliefen die Operationen der preußischen Armee indessen unter völlig anderen Vorzeichen. Im August war Friedrich II. nach seiner schweren Niederlage bei Kunersdorf nur mit Glück einer drohenden Vernichtung entgangen. In der Folgezeit konzentrierte sich seine Operationsführung wieder auf die österreichische Hauptarmee unter Feldmarschall Daun sowie die Reichsarmee und damit auf Sachsen. Mitte November standen sich die Heere westlich von Dresden gegenüber. ${ }^{14} \mathrm{Da}$ die Elbe zugefroren und die Umgebung Dresdens ausfouragiert war, hoffte der preußische König darauf, dass Daun aufgrund des einbrechenden Winters und der zunehmenden Versorgungsprobleme sich alsbald über das Erzgebirge nach Böhmen zurückziehen und ihm Sachsen damit überlassen würde. ${ }^{15} \mathrm{Um}$ ihn in seinem Entschluss zu bestärken, hatte Friedrich II. ein preußisches Korps unter dem Oberst Kleist nach Böhmen entsandt, welches mit Mitteln des „Kleinen Krieges“ Überfälle unternahm, Magazine zerstörte und damit die langen Versorgungswege der Armee Dauns be-

13 Das Lager bildete etwa ein Dreieck mit Seitenlängen zwischen neun und zehn Kilometern. Die Mitnahme der angegebenen Menge an Vorräten entsprach aber durchaus den Gepflogenheiten der Zeit, wonach ein Soldat neben seiner schweren Ausrüstung kaum mehr Brot als für drei bis fünf Tage mit sich führen konnte. Zudem war Brot ohne Konservierungsstoffe nicht länger als neun Tage haltbar. Entsprechend wichtig war daher die Vorbereitung des "Sammelplatzes“, wie etwa Hoyer betont: Das Lager muß auf zwey Monate mit Lebensmitteln verseben seyn. [...] Es muß eine dreyfache Chargirung für die Artillerie und Infanterie vorbanden seyn. In der Beurteilung der taktischen Nachteile des Lagers waren sich die Zeitgenossen weitgehend einig; voN SAlisch, Treue Deserteure (wie Anm. 1), S. 73, 81-83, 90, 98; LuH, Kriegskunst (wie Anm. 10), S. 50 f.; von Hoyer, Versuch (wie Anm. 11), S. 50, 57, 69.

14 Daun befand sich ab dem 17. November mit der österreichischen Hauptarmee hinter dem „Plauenschen Grund“, wobei sich sein rechter Flügel an Dresden lehnte. Die Reichsarmee stand südlich von Pirna bei Cotta und Berggießhübel. Das preußische Heer befand sich um den 18. November bei Wilsdruff. Das Korps des General Fink marschierte ab dem 13. November von Nossen über Freiberg und Dippoldiswalde nach Hausdorf und Maxen, wo es am 18. November eintraf; Generalstab, Minden und Maxen (wie Anm. 3), Skizze 51.

15 Hinzu kam der Umstand, dass sich Friedrich II. zu dieser Zeit wohl auch Hoffnungen auf einen baldigen Friedensschluss machte. Der Besitz Sachsens konnte somit seine Position in eventuell bevorstehenden Friedensverhandlungen deutlich verbessern; Albert Naudé (Red.), Politische Correspondenz Friedrichs des Großen, Bd. 18, Berlin 1891, Nr. 11594; Mollwo, Die Kapitulation (wie Anm. 3), S. 39 f., 49. 
drohte. ${ }^{16}$ Eine weitere Maßnahme war die Entsendung des Korps des Generalleutnants von Fink in die Gegend des fast 30 Kilometer entfernten Maxen und damit in den Rücken der Österreicher, während die preußische Hauptarmee bis Wilsdruff vorrückte. Finks Auftrag lautete unter anderem, alles was mit schwacher und schlechter Escorte [...] durch will, zu attaquiren und allen möglichen Tort zu thun. Hingegen kommt was starkes, oder hat der Feind eine gute Disposition, so könnt ibr solche passiren lassen. ${ }^{17}$ Am 18. November bezog Fink auf dem Hochplateau bei Maxen ein Lager. Das Gelände war auf den ersten Blick für die Durchführung seines Auftrages geeignet: durchschnitten, bergig und unübersichtlich. Es ermöglichte jedoch auch dem Feind eine unbemerkte Annäherung und schränkte die Wirkungsmöglichkeiten der preußischen Geschütze ein. Dies zwang Fink dazu, seine Truppen mit Front nach mehreren Seiten aufzustellen, wodurch das Verteidigungssystem geschwächt wurde. Die herrschende Kälte erschwerte das Anlegen von größeren Befestigungswerken enorm. ${ }^{18}$ Ungeachtet dieser Probleme hielt Fink - dies ist eine Parallele zu Pirna - seine Stellung für unangreifbar. In diesen Tagen herrschten sowohl bei ihm selbst als auch beim König keinerlei Zweifel am Gelingen der Operation: Übrigens ist aus allen Umständen zu schließen, dass Daun sich gewiss präparirt um nach Böhmen zu gehen. ${ }^{19}$

Weiterhin relevant erscheint die unterschiedliche Führungskultur in den jeweiligen Armeen. Dabei stehen die Rollen der Fürsten beziehungsweise obersten Kriegsherren und der Heerführer im Fokus. Die Möglichkeiten Friedrichs II. als Feldherr waren beinahe unbegrenzt. Er war bekanntlich der „roi-connétable“, der König-Feldherr. Durch diese Doppelrolle stand ihm die politische Tragweite seines militärischen Handelns ständig vor Augen. Seine persönliche Anwesenheit auf dem jeweiligen Kriegsschauplatz konnte jedoch nicht nur bei seinen Gegnern

16 Die Bedrohung sollte vor allem den Handelswegen gelten, die über Nollendorfer Pass, Geiersberg und Graupener Pass auf böhmischer Seite in die Gegend von Teplitz, Kulm und Aussig führten. $\mathrm{Zu}$ den Übergängen über das Erzgebirge siehe auch InGOLF Grässler, Pässe über das Erzgebirge. Paßwege und Paßstraßen zwischen Freiberger und Zwickauer Mulde im Mittelalter, in: Rainer Aurig/Steffen Herzog/Simone Lässig (Hg.), Landesgeschichte in Sachsen. Tradition und Innovation, Dresden 1997, S. 97-108; Politische Correspondenz (wie Anm. 15), Bd. 18, Nr. 11588, 11595.

17 Schreiben Friedrichs II. an Fink vom 15. November 1759; Politische Correspondenz (wie Anm. 15), Bd. 18, Nr. 11593.

18 Ein Kriegsteilnehmer berichtet aus den Winterquartieren in der Umgebung Dresdens im Winter 1759/60: Die Kälte ist so excesiv gewesen, daß uns viele Leute auf der Schildwacht erfroren sind. [...] Wir hatten uns ganz in die Erde eingegraben und darin Kamine verfertiget. Einige Offiziers ließen sich kleine Häuser von Holz und Bretern machen, worinnen ein gemauerter Kamin, Thüre und Fenster war.; Tagebuch eines Preußischen Offiziers (wie Anm. 12), S. 389. Einige der bei Maxen vorhandenen Geländeverstärkungen waren bereits in vorangegangenen Feldzügen des Siebenjährigen Krieges angelegt worden und konnten allenfalls der Täuschung des Gegners als einer effizienten Verteidigung dienen; Tielke, Das Treffen bey Maxen (wie Anm. 3), S. 16 f.

19 Brabant, Kesselsdorf und Maxen, S. 118-130 (wie Anm. 3); Mollwo, Die Kapitulation (wie Anm. 3), S. 48, 55, 57-60. 
Respekt, ja vielleicht sogar „lähmende Ratlosigkeit“ auslösen.20 Die Kritik des Königs war bei seinen eigenen Generälen gefürchtet, was dazu führte, dass diese oft befangen agierten. Zwar ließ der autoritäre, allgegenwärtige und - seiner Meinung nach - in militärischen Angelegenheiten unfehlbare Friedrich den Unterführern, denen er vertraute, durchaus Raum zum selbstständigen Handeln beziehungsweise forderte es sogar. ${ }^{21}$ Diese Ansätze einer „Auftragstaktik“ bedeuteten jedoch auch, dass der Auftrag a) klar formuliert, b) auch so verstanden und c) der Auftragsempfänger geeignet ist, auf eine solche Art geführt zu werden. Auffällig ist, dass es zwischen dem König und den Kommandanten selbstständig operierender Teile der Armee im Verlaufe des Krieges immer wieder zu Spannungen kam. ${ }^{22}$ Prominente Beispiele hierfür sind etwa die bekannten Auseinandersetzungen mit seinen Brüdern Heinrich und August Wilhelm. Auch im Hinblick auf die ab dem 14. November zwischen dem preußischen König und General Fink geführte Korrespondenz ergeben sich Fragen in allen der drei oben genannten Punkte. ${ }^{23}$ Fink, der aus russischen Diensten in das preußische Heer eingetreten war, galt als sehr talentierter und human denkender Vertreter der jüngeren Generalität. ${ }^{24}$ Friedrich II. schätzte ihn sehr und soll ihn sogar als „zweiten Turenne“ gelobt haben..$^{25}$ Fink war aber auch für das peinliche Befolgen von Befehlen bekannt. ${ }^{26}$ Seine Entsendung in die Gegend von Maxen schien vom König sehr kühn geplant, was einige preußische Offiziere auch kritisierten. ${ }^{27}$ Der Auftrag erforderte von Fink

20 Lotz, Kriegsgerichtsprozesse (wie Anm. 3), S. 45-59; Kunisch, Friedrich (wie Anm. 5), S. 345, 433 f.; Beatrice Heuser, Clausewitz lesen! Eine Einführung, München 2005, S. 80 f.; Schieder, Friedrich (wie Anm. 7), S. 185-187; Ullrich Marwitz, Friedrich der Große als Feldherr, in: Friedrich der Große und das Militärwesen seiner Zeit (Vorträge zur Militärgeschichte 8), hrsg. vom Militärgeschichtlichen Forschungsamt, S. 73-92; Beatrice Heuser, Graf Guibert und Friedrich der Große als Helden des Siebenjährigen Krieges, in: Historische Mitteilungen der Ranke-Gesellschaft 18 (2005), S. 31-43.

21 Zur Bedeutung des selbstständigen Handelns der Generäle bei Friedrich II.: LotZ, Kriegsgerichtsprozesse (wie Anm. 3), S. 30, 32-36, 44.

22 Schieder, Friedrich (wie Anm. 7), S. 186.

23 Der teilweise zweideutige Inhalt der jeweiligen Schreiben ist wiedergegeben u. a. bei: Mollwo, Die Kapitulation (wie Anm. 3), S. 48-52; Winter, Die kriegsgeschichtliche Überlieferung (wie Anm. 3), Anhang II; Politische Correspondenz (wie Anm. 15), Bd. 18, Nr. $11587 \mathrm{f}$.

24 Die „Schweriner“ Denkschule, die anstelle des scharfen Drills eher auf moderne pädagogische Mittel setzte, wurde wesentlich durch Generalfeldmarschall Kurt Christopher Graf von Schwerin (1684-1757) geprägt. Sie bildete einen Gegenpol zu den Ansichten des „Alten Dessauer“; Jürgen KloOsterhuis, Kritik vor der Krise. „Gedanken über militärische Gegenstände“ zweier preußischer Generäle vor und nach dem Siebenjährigen Krieg, in: Jürgen Kloosterhuis/Sönke Neitzel (Hg.), Krise, Reformen - und Militär. Preußen vor und nach der Katastrophe von 1806 (Forschungen zur brandenburgischen und preußischen Geschichte 10), Berlin 2008, S. 133, 136.

26 Generalstab, Minden und Maxen (wie Anm. 3), S. 217.

27 Schüssler, Friedrich (wie Anm. 2), S. 386 f. 
ein hohes Maß an Selbstständigkeit. Zum heiklen Inhalt seines Auftrages kam die Tatsache, dass er sich zu diesem Zeitpunkt wohl unter „Erfolgsdruck“ befand. Sein persönliches Ansuchen beim König um eine nähere Erläuterung seiner Mission wurde von diesem sehr ungnädig aufgenommen. Zudem kritisierte der König die anfängliche Verteilung von Finks Truppen in der Gegend um Maxen. Um keinen zusätzlichen Unwillen auf sich zu ziehen, wird Fink durch die Präsenz des Königs eher befangen gehandelt und auf weitere Vorstellungen verzichtet haben. Ein Hinweis hierauf ist die Tatsache, dass er die ihm unangenehme Position ${ }^{28}$ bei Maxen letztendlich klaglos bezog, weil diese vom König eben mehrfach als geeignet bezeichnet wurde. Ähnlich verhielt es sich mit dem Sichern der Rückzugswege: So wie es die sächsische Armee bei Pirna versäumte, die wichtigen Übergänge nach Böhmen zu besetzen, wurde auch Fink kurzerhand befohlen, auch die zur Sicherung eingesetzten Truppen an sich zu ziehen. ${ }^{29}$

Dass die personelle Einheit von König und Feldherr auf den Schlachtfeldern dieser Zeit jedoch eine Ausnahme darstellte, zeigt ein Perspektivwechsel nach Sachsen und Österreich. Auch wenn es keinen „roi-connétable“ gab, sah sich ein Feldherr des Ancien Régime vielfältigen Zwängen ausgesetzt. ${ }^{30} \mathrm{Im}$ Staatsverständnis von Kurfürst Friedrich August II. besaß das Militär keinesfalls einen vergleichbaren Stellenwert wie etwa in Preußen. ${ }^{31}$ Seine Grenzen fand Rutowski dem-

Schreiben Finks an Friedrich II. vom 19. November; WINTER, Die kriegsgeschichtliche Überlieferung (wie Anm. 3), S. $141 \mathrm{f}$.

29 Der Darstellung Finks zufolge wurde er am 13. November sehr ungnädig vom König empfangen. Dieser soll ihm erklärt haben, dass er keine Diffikultäten leiden könne, und mit den Worten entlassen haben: Herr, mache er dass er fortkömmt!; zitiert nach JüRGEN Kloosterhuis (Hg.), „Berichtigung einiger Stellen in der Lebensbeschreibung des Generals von Fink welche dessen Gedanken über militairische Gegenstände vorangesetzt ist", Berlin 1789, in: Krise, Reformen - und Militär (wie Anm. 24), S. 255 f.; Am 18. November legte Friedrich II. Fink in einem Schreiben nahe, alle seine Truppen zu einem Klumpen, d. h. auf engem Raume, zu konzentrieren, was in der Rückschau als großer taktischer Fehler gewertet wurde. Damit wurde die Sicherung der Rückzugsund Verbindungswege verhindert; Politische Correspondenz (wie Anm. 15), Bd. 18, 11605; Kunisch, Friedrich (wie Anm. 5), S. 239; Generalstab, Minden und Maxen (wie Anm. 3), S. 187.

30 Ein biografischer Abriss zu Rutowski findet sich bei: von SAlisch, Treue Deserteure (wie Anm. 1), S. 30-45.

31 Innerhalb des Reiches besaß Kursachsen im 18. Jahrhundert dennoch hinter Preußen und Österreich die drittstärkste Armee. Bei einer Einwohnerzahl von ca. 1,6 Millionen verfügte Kursachsen um 1750 über etwa 25.000 Soldaten. Der prozentuale Anteil der Streitkräfte an der Gesamtbevölkerung betrug demnach rund 1,6 Prozent. Etwa zur gleichen Zeit (1756) verfügte Preußen bei etwa 2,9 Millionen Einwohnern über ein Heer von 153.000 Mann (5,3\%), woraus eine deutlich höhere gesellschaftliche Militarisierung resultierte; Kroll, Soldaten im 18. Jahrhundert (wie Anm. 1), S. 71, 73; Olaf Groehler, Die Kriege Friedrichs II., Berlin 1990, S. 74; Bernhard R. Kroener, „Das Schwungrad an der Staatsmaschine?" Die Bedeutung der bewaffneten Macht in der europäischen Geschichte der Frühen Neuzeit, in: Bernhard R. Kroener/Ralf Pröve (Hg.), Krieg und Frieden. Militär und Gesellschaft in der Frühen Neuzeit, Paderborn 1996, S. 6 f.; siehe im Detail auch: Bernhard R. Kroener, Wirtschaft und Rüstung der europäischen Großmächte im Siebenjährigen Krieg. Überlegungen zu einem ver- 
zufolge weniger im Willen des Monarchen, der hinsichtlich seiner Herrschaftstechnik auf die Expertise der jeweiligen „Fachleute“ setzte und seinen Feldmarschall entsprechend agieren ließ, sondern vielmehr in den Anweisungen des beinahe übermächtigen Premierministers Heinrich Graf von Brühl (1700-1763) und vor allem in den knappen Staatsfinanzen. Hier bewegte sich der Feldmarschall in einem enormen Spannungsfeld von militärischer Notwendigkeit und politischer Beschränkung. Misswirtschaft und Kriegskosten zwangen den als guten Organisator, als human-aufgeklärten und zuweilen nachgiebigen Menschenführer bekannten Feldmarschall, immer neue Einsparungspotenziale zu identifizieren. ${ }^{32}$ War schon das Gelingen der Zusammenziehung des Heeres bei Pirna einzig das Verdienst Rutowskis gewesen, so ließ ihn die sächsische Staatsführung auch während der Belagerung gewähren. Der sächsische Monarch besichtigte das Lager kaum. Abgeschottet in der Privatheit seines Hauptquartiers und fast bis zuletzt gut versorgt verlebte Friedrich August mangels Identifikation mit den Leiden seiner Truppen die Wochen der Einschließung recht „zivilisiert“. ${ }^{33}$ Aufgrund der passiven Haltung des sächsischen Monarchen lastete die Verantwortung für die Geschicke der Armee auf Rutowskis Schultern. Interessanterweise führte aber fast ausschließlich Graf Brühl die lebenswichtige Korrespondenz mit dem österreichischen Heer bezüglich eines möglichen Entsatzes. ${ }^{34}$ Hinzu kam für Rutowski das „Kainsmal“ der Erfolglosigkeit: Im Jahre 1745 hatte der sächsische Oberkommandierende die Niederlage bei Kesselsdorf gegen die preußische Armee hinnehmen müssen. Im September 1756 waren Rutowskis Erfolgsaussichten bei Pirna wiederum sehr gering. Oder zugespitzt ausgedrückt: Er war als Feldherr schon beinahe besiegt, ehe der Krieg wirklich begann.

Feldmarschall Leopold Joseph Graf von Daun (1705-1766), um auch den Befehlshaber der österreichischen Streitkräfte bei Maxen hier kurz zu betrachten, stand für ein drittes Modell: Er war als Oberkommandierender nur einer von zahl-

gleichenden Ansatz, in: Ralf Pröve/Bruno Thoß (Hg.), Kriegerische Gewalt und militärische Präsenz in der Neuzeit. Ausgewählte Schriften, Paderborn 2008, S. 215-239.

Zwischen 1746 und 1756 sanken die Einnahmen der Generalkriegskasse von 3,9 auf 1,9 Millionen Taler. Die Stärke des Heeres wurde von fast 50.000 Mann (1746) auf unter 25.000 Mann (1756) reduziert; von SAlisch, Treue Deserteure (wie Anm. 1), S. 46-48; Bruno Franze, Die Heeres-Reduktion unter Brühl 1746-1756. Ein Beitrag zur Heeres- und Finanzgeschichte, Leipzig 1921.

33 Zum „zivilisierten Habitus" von führenden Militärs und Politikern sowie zur Idealisierung des militärischen Führers aus einer Gemengelage aus „Liebe und Zärtlichkeit" und "Furcht und Angst" siehe Sabine A. Haring/Helmut Kuzmics, Einleitung, in: Dies., Das Gesicht des Krieges: Militär aus emotionssoziologischer Sicht (Schriftenreihe der Landesverteidigungsakademie 5), Wien 2008, S. 24 f., 27, 57; MARTIN van Creveld, Kampfkraft. Militärische Organisation und Leistung der deutschen und amerikanischen Armee 1939-1945, Graz 2007, S. 189 f.

Von Salisch, Treue Deserteure (wie Anm. 1), S. 292. 
reichen Protagonisten im „System von verwickelten Befehlskompetenzen“.35 Daun war stark von den Entscheidungen seiner Kaiserin Maria Theresia, des Staatsrates sowie der Hofkammer und des ihr zugehörigen Wiener Hofkriegsrates abhängig. Die Schwerfälligkeit in der Zusammenarbeit dieser Gremien verhinderte oftmals eine dynamische Operationsführung und beschnitt Dauns Entscheidungsfreiheit und Entschlussfreudigkeit im Felde. Vielen galt er daher als Zauderer. Friedrich II. hatte häufig nur Spott für ihn übrig. ${ }^{36}$ War Dauns vorsichtige Kriegführung vielleicht repräsentativer für das Zeitalter des Absolutismus als diejenige Friedrichs II., so war er dennoch häufig in der Lage, die Schwächen seines Gegners auszunutzen, so etwa in den Gefechten bei Kolin 1757, Hochkirch 1758 und bei Maxen.

\section{Die Umschließung}

Bei der Betrachtung von Pirna und Maxen fällt wie erwähnt auf, dass die jeweiligen Kommandierenden glaubten, der Gegner würde sich nicht mit einem Gefecht aufhalten. In Pirna hoffte Rutowski, Friedrich II. würde direkt nach Böhmen weiterziehen. Damit hatte er die Absicht des Gegners jedoch falsch beurteilt. Der preußische König konnte es sich nicht leisten, eine voll kampfbereite Armee in seinem Rücken an der strategisch wichtigen Elbe stehen zu lassen. Friedrich II. wusste um den mangelhaften Zustand der sächsischen Armee und um ihre geringen Vorräte. Er hatte somit berechtigte Hoffnung, Rutowskis Truppen gewissermaßen „im Vorbeigehen“ zur Aufgabe zu zwingen. Am 13. September artikulierte er diese Absichten in aller Deutlichkeit: Also muß ich die ganze Armee einstellen [...] die Armee muß mit mir marschieren und mir den Eid der Trene leisten. ${ }^{37}$ Aus

35 Daun bekleidete neben dem Oberkommando auch das Amt eines Staatsministers (ab 1760) und wurde 1762 Präsident des Hofkriegsrates. Auch eine von Kaunitz 1761 durchgeführte Reform der Zentralbehörden konnte den „Wirrwarr“ an Zuständigkeiten nicht vollkommen beseitigen; Kunisch, Friedrich (wie Anm. 5), S. 346 f.; SCHIEdER, Friedrich (wie Anm. 7), S. 185. Zur österreichischen Armee im Siebenjährigen Krieg exemplarisch: Christopher Duffy, Sieben Jahre Krieg 1756-1763. Die Armee Maria Theresias, Wien 2003.

36 So wurde Daun von Friedrich II. häufig als dicke Exzellenz oder der geweibte Hut bezeichnet. Anstatt dem preußischen Heer entgegen zu treten, würde der zögerliche Daun es lieber vorziehen, auf hohen Bergen zu hocken. Friedrichs Spott wurde unter anderem herausgefordert durch die angebliche Verleihung eines geweihten Hutes und Degens an Daun nach dessen Sieg bei Hochkirch 1758 durch Papst Clemens XIII., welche der Vatikan und der Wiener Hof jedoch amtlich dementierten; SchüssLeR, Friedrich (wie Anm. 2), S. 354, 363, 385, 535; Breve des Papstes an Feldmarschall Daun (Mai 1759) in: Woldemar von SeIdlitz (Hg.), Friedrich der Große, Gedanken und Erinnerungen. Werke, Briefe, Gespräche, Gedichte, Erlasse, Berichte und Anekdoten, Essen 1990, S. 60 f.; Brabant, Kesselsdorf und Maxen (wie Anm. 3), S. 114 f., 148 f.

37 Bericht des sächsischen Generals Arnim über seine Entsendung zu Friedrich II.; zitiert nach HöHne, Die Einstellung (wie Anm. 1), S. 37 f. 
seinem anfänglichen Optimismus sollte aber bald Verzweiflung werden: Bereits nach den ersten Erkundungen musste Friedrich II. resigniert feststellen, dass es unmöglich ist, dieses verdammte Lager anzugreifen. ${ }^{38}$ Anfang Oktober - die Lage war unverändert - dann der Höhepunkt: Die Sachsen verderben mir die ganze Campagne! 39

Auch bei Maxen schätzte der preußische König und demzufolge auch General Fink den Gegner falsch ein. Nicht der erwähnte Rückzug in die Winterquartiere geschah, sondern das Unerwartete trat ein: Der „Zauderer“ Daun handelte rasch und energisch. Durch seine leichten Truppen hatte er alsbald Kenntnis von der Entsendung Finks. Dessen Position wurde im österreichischen Hauptquartier als sehr bedrohlich empfunden. Daun beschloss daher, mit seinen Truppen sowie der Reichsarmee gegen Finks Korps konzentrisch vorzugehen. Bis zum Abend des 19. November hatten seine Truppen das preußische Korps abgeriegelt, während Finck sich in der Hoffnung auf Hilfe durch den König abwartend verhielt. ${ }^{40}$ Am Morgen des 20. begann der trotz numerischer Überlegenheit schwierige Angriff der österreichischen Truppen auf das Plateau bei Maxen. Das Vorgehen von mehreren Seiten bewirkte, dass sich Finks Vortruppen rasch auf die Hauptstellung nach Maxen zurückzogen, die dann am Nachtmittag heftig umkämpft wurde. ${ }^{41}$ Bemerkenswert erscheint in diesem Zusammenhang, dass die österreichischen Truppen auf eher zeituntypische Weise in Kolonnen, d. h. tief gestaffelt, und unter Ausnutzung natürlicher Deckung gegen die teilweise vereisten Höhen bei Maxen vorgingen. Das Voranbringen der Geschütze und Pferde scheint ihnen dabei große Mühe bereitet zu haben. Für den teilweise geringen Widerstand auf preußischer Seite macht die ältere Literatur vor allem die fehlende „Begeisterung und Vaterlandsliebe“ der vielen gepressten Sachsen, Russen und Österreicher in den preußischen Infanterieregimentern verantwortlich. ${ }^{42}$ Diese mangelnde Standhaftigkeit ist nicht

38 Schreiben Friedrichs II. an Feldmarschall Schwerin vom 18. September 1756; zitiert nach HöHne, Die Einstellung (wie Anm. 1), S. 34.

39 Schreiben Friedrichs II. an General Winterfeldt vom 7. Oktober 1756; Politische Correspondenz (wie Anm. 15), Bd. 18, Nr. 8171.

40 Am 19. November teilte Fink dem König mit, er habe Verpflegung bis zum 23. November, er erwarte keinen Angriff auf seine vorteilhafte Stellung und - sollte dieser Fall doch eintreten - rechne er fest mit einem Entsatz; WINTER, Die kriegsgeschichtliche Überlieferung (wie Anm. 3), S. 141 f.; Generalstab, Minden und Maxen (wie Anm. 3), S. 195 f.

41 Fink wurde später kritisiert, in dieser Phase das Gelände nicht ausreichend genutzt zu haben. Dies betrifft vor allem die südwestlich von Maxen gelegene Enge von Reinhardsgrimma, durch welche später der Angriff Dauns auch erfolgte. Durch eine nachhaltige Sperrung dieses Geländeabschnittes sowie die Besetzung der Höhen mit preußischen Truppen hätte Fink den Feind wohl aufhalten und damit einen entscheidenden Zeitgewinn erzielen können; WINTER, Die kriegsgeschichtliche Überlieferung, S. 57 f.

42 Der erfolgreiche Sturmangriff der Österreicher begann nach einer Kanonade etwa um drei Uhr nachmittags und muss für Finks Truppen etwas überraschend erfolgt sein. Die vereisten Wege wurden von den österreichischen Soldaten durch Erde und Reisig gangbar gemacht. Feldmarschall Daun soll angesichts des schwierigen Geländes um die preußische Stellung zeitweise gezögert haben, den Angriff fortzusetzen. Durch die 
unwahrscheinlich, da beispielsweise ins preußische Heer gepresste sächsische Soldaten im Verlauf des Siebenjährigen Krieges bei mehreren Gelegenheiten zum Gegner überliefen, etwa bei der Eroberung von Zittau und der Kapitulation von Schweidnitz im Jahre 1757.43 Zudem scheinen das Feuer der österreichischen Geschütze und die Tatsache, dass Daun den Angriff in diesem ungünstigen Gelände wider Erwarten durchführen ließ, eine ungemeine moralische Wirkung erzielt zu haben. ${ }^{44}$ Von Beginn an, so berichtet ein Kriegsteilnehmer, herrschte unter den Truppen Confusion. ${ }^{45}$ Dieses Durcheinander scheint den Zusammenhalt der Formationen, denen im Kampfgetümmel auch eine Schutzfunktion zukam, negativ beeinträchtigt zu haben. ${ }^{46}$ Die Folge waren das „kollektive Phänomen der Angst“ und die „irrationalen Aspekte der häufig eintretenden Massenpaniken, aber auch der Desertion“, welche häufig militärische Niederlagen herbeiführten. ${ }^{47}$ Gerade in diesem Zusammenhang ist nochmals auf die vorangegangene Schlacht bei Kunersdorf zu verweisen. Offenbar genügten angesichts des Erlebten bei vielen Soldaten nur geringe Anstöße, damit sie mehr der Stimmung anstatt der Disziplin gehorch-

Erkundungsergebnisse der Feldingenieure wurde er jedoch in seinem Angriffswillen bestärkt. Durch einen offenbar übereilten und fehlgeschlagenen Gegenangriff der preußischen Grenadiere gelang den österreichischen Truppen nach relativ kurzer Zeit der Einbruch in die Maxener Stellung; Generalstab, Minden und Maxen (wie Anm. 3), S. 199-206, 219; Mollwo, Die Kapitulation (wie Anm. 3), S. 62-71; Brabant, Kesselsdorf und Maxen (wie Anm. 3), S. 167-180; Tielke, Beyträge (wie Anm. 3), S. 12 f.; Journal, von dem Finkischen Corps bei Maxen, in: Sammlung ungedruckter Nachrichten, so die Geschichte der Feldzüge der Preußen von 1740 bis 1779 erläutern, 2. Teil (Anonym; Neudruck der Ausgabe Dresden 1782-1785), Bad Honnef 1983, S. 600-605; in der Anlage des Gefechts ergeben sich etliche Parallelen zur „modernen“ Schlacht bei Burkersdorf im Jahre 1762, in welcher es der preußischen Armee gelang, die österreichische Stellung am Rande des Eulengebirges unweit Schweidnitz zu erobern; Duffy, Friedrich (wie Anm. 1), S. 327-345, 468; Eberhard Kessel, Das Ende des Siebenjährigen Krieges 1760-1763. Torgau und Bunzelwitz/Schweidnitz und Freiberg, hrsg. von Thomas Lindner, Paderborn 2007, S. 648-664, Karte 20.

43 Von SAlisch, Treue Deserteure (wie Anm. 1), S. 247 f.

44 Zudem ließ der gefrorene Boden die Geschosse springen und erhöhte deren Gefährlichkeit; D. KerLer (Hg.), Tagebuch des Musketiers Dominicus (Altpreussischer Kommiss. Offiziell, offiziös und privat), Osnabrück 1972 (Neudruck der Ausgabe 1891), S. 75.

45 Journal, von dem Finckischen Corps (wie Anm. 42), S. 601 f. Das zivile Fuhrwesen spielte für die Versorgung frühneuzeitlicher Heere eine entscheidende Rolle; LuH, Kriegskunst (wie Anm. 10), S. 42, 49 f.; Отто Büsch, Militärsystem und Sozialleben im alten Preußen 1713-1807. Die Anfänge der sozialen Militarisierung der preußischdeutschen Gesellschaft, Frankfurt a. M. 1981, S. 25 f.

46 Michael Sikora, Das 18. Jahrhundert: Die Zeit der Deserteure, in: Ulrich Bröckling/ Michael Sikora (Hg.), Armeen und ihre Deserteure. Vernachlässigte Kapitel einer Militärgeschichte der Neuzeit, Göttingen 1998, S. 101; John KeEgan, Das Antlitz des Krieges. Die Schlachten bei Azincourt 1415, Waterloo 1815 und an der Somme 1916, Frankfurt a. M. 2007, S. 215, 225.

47 Vgl. Kroener, Das Schwungrad (wie Anm. 31), S. 18. 
ten und geordnete Truppenkörper sich somit in eine flüchtende Menge verwandelten. ${ }^{48} \mathrm{Als}$ sich die österreichische Infanterie eine Bresche verschaffte und ins Dorf Maxen eindrang, liefen viele preußische Soldaten aus Angst, vom Korps abgeschnitten zu werden, zurück unter die Bagage, aus welcher sie gegenwärtig nicht mebr zu sammeln waren. ${ }^{49}$ Als die Dämmerung den kurzen Novembertag beendete und das Gefecht unterbrach, befand sich Fink in einer schwierigen Situation: Der größte Teil seiner Artillerie war den Österreichern in die Hände gefallen. Seine verbliebenen Truppen waren auf eine Auffangstellung bei Schmorsdorf, etwa 1,5 Kilometer nordwestlich von Maxen, zusammengedrängt worden. Die noch einsatzfähigen Soldaten hockten zusammen mit den Verwundeten unter erbärmlichen Umständen bei klirrendem Frost in Häusern und Kellern. ${ }^{50}$ Bei der herrschenden Dunkelheit war es für die militärischen Führer schwer, ihre Truppen $\mathrm{zu}$ ordnen, ein genaues Lagebild zu erhalten und mögliche Ausweichwege zu erkunden. Mit der Wahl seiner Stellung, seinem anfänglich passivem Verhalten und der zu raschen Preisgabe entscheidender Geländeabschnitte hatte sich Fink also in eine Situation manövriert, aus der es kaum einen Ausweg mehr gab.

Die schnelle Umschließung durch den Gegner führte in Pirna wie in Maxen dazu, dass der Kontakt der belagerten Truppen zur Außenwelt eingeschränkt oder gänzlich unterbrochen wurde. ${ }^{51}$ Dies hatte zweierlei Folgen: Einmal die Ungewissheit bei den Eingeschlossenen hinsichtlich des Vorankommens eines Entsatzversuches, zum anderen die fehlende Kenntnis bei den Entsatztruppen beziehungsweise im preußischen Hauptquartier bezüglich der Lage vor Ort. Das schwierige Gelände, die schlechten Witterungsumstände sowie die Präsenz gegnerischer Truppen führten in beiden Fällen dazu, dass die Entsatztruppen nur sehr mühsam voran kamen. Dass es in Maxen nicht nur zu einer kleineren Action ${ }^{52}$, sondern zu einer Hauptaffaire gekommen war, wurde dem preußischen Hauptquartier in Wilsdruff durch den Geschützdonner, die Rauchwolken und den

48 Zur Panik im Gefecht siehe KeEgan, Das Antlitz des Krieges (wie Anm. 46), S. 201-203; Zur Rolle von Emotionen im Militär: Haring/Kuzmics, Einleitung (wie Anm. 33), S. 44-58.

49 Journal, von dem Finckischen Corps (wie Anm. 42), S. 603. Vgl. mit dem Beispiel des preußischen Freibataillons Salemnon 1759 bei LuTz VoigtLÄNDER, Die preußischen Kriegsgefangenen der Reichsarmee 1760/1763 (Duisburger Studien 22), Duisburg 1995, S. 18.

50 Kerler, Tagebuch des Musketiers Dominicus (wie Anm. 44), S. 75 f.

51 Winter, Die kriegsgeschichtliche Überlieferung (wie Anm. 3), S. 56; Generalstab, Minden und Maxen (wie Anm. 3), S. 218.

52 Am 18. November schrieb Fink an Friedrich II.: Ich glaube schwerlich, dass ich eine Affaire Generale mit die Leute bekommen werde. Am Abend desselben Tages sandte Friedrich die zweideutige Order an Fink: Er wird entweder mit den Reichern [Reichsarmee, Anm.] oder mit Sinceren [österreichisches Korps des Generals Sincère] einen Gang haben. Noch am selben Tage ergänzte Friedrich: Generalaffaire rechne nicht, muss noch nicht sein, wäre nicht gut; aber Chicanen!; Politische Correspondenz (wie Anm. 15), Bd. 18, 11609, 11610; WINTER, Die kriegsgeschichtliche Überlieferung (wie Anm. 3), S. 120. 
Feuerschein des brennenden Dorfes Maxen angedeutet. ${ }^{53}$ Daraufhin entsandte Friedrich II. am 20. November zur Unterstützung Finks ein Korps unter General Hülsen, über dessen Anmarsch Fink jedoch keine Kenntnis besaß. Die Entsatztruppen hatten zudem viel Mühe, wie ein Kriegsteilnehmer berichtet: Die Artillerie blieb die Nacht unter freiem Himmel auf dem Wege liegen, weil sie an manchen Orten drei bis vier Stunden gebrauchte, einen Berg zu ersteigen; denn da es stark gefroren hatte und die Pferde nicht beschlagen waren; musste das Geschütz mehr durch Menschen hinauf gezogen werden. ${ }^{4}$ Trotz dieser Strapazen konnte sich Hülsen nicht weiter als auf etwa 15 Kilometer an das eingeschlossene Korps annähern. Während seines Anmarsches hatte er keine genauen Kenntnisse über die Position Finks sowie die Lage vor Ort. ${ }^{55}$

Auch in Pirna erwartete man dringend Entsatz. Dieser sollte aber nicht nur helfen, die taktische Pattsituation aufzulösen. Der Hauptgrund war mit zunehmender Dauer der Belagerung ein anderer, nämlich der Hunger. Die sächsische Generalität ließ die Soldaten mit der Zeit immer rücksichtsloser gegen die Zivilbevölkerung vorgehen. Die einzige Vorsorge, so Rutowski schon bald nach Beginn der Belagerung, müsse auf die Armee gerichtet seyn und nicht auf die unnützen Mäuler der Bevölkerung. Dem zufolge wurden Häuser und Scheunen aufgebrochen; Nahrungsmittel, Vieh und Futter beschlagnahmt. Entsprechend litten die Einwohner von Pirna und den wenigen im Lager befindlichen Ortschaften mindestens ebenso wie die Soldaten. ${ }^{56}$ Eine anonyme Quelle berichtet über die Situation kurz vor dem Ausbruch: Es wurde von Tage zu Tage schlechter bey uns: denn die Pferde, so auf der Weide herum giengen, und nichts mebr zu fressen fanden, fielen um und krepirten für Hunger. ${ }^{57}$ Und der sächsische Infanterist Gottfried

53 Da es zu diesen Zeit noch kein „rauchschwaches“ Pulver gab, breitete sich der Qualm der Musketen und Geschütze erheblich aus. Es ist durchaus möglich, dass auch der Geschützlärm über derart weite Strecken vernehmbar war. Die etwa 50 Kilometer (Luftlinie) entfernt stattfindende Schlacht bei Lobositz soll für die bei Pirna eingeschlossenen Sachsen ebenfalls zu hören gewesen sein; LuH, Kriegskunst (wie Anm. 10), S. 137; Keegan, Das Antlitz des Krieges (wie Anm. 46), S. 161-163; von Salisch, Treue Deserteure (wie Anm. 1), S. 105; Generalstab, Minden und Maxen (wie Anm. 3), S. 206-208.

54 Zitiert nach Generalstab, Minden und Maxen (wie Anm. 3), S. 207.

55 Seine Entsatztruppen stießen etwa bis Dippoldiswalde vor, wo er sich mit den aus Böhmen zurückbeorderten Truppen Kleists vereinigte. Der Anmarsch wurde durch den Lauf der Weißeritz zusätzlich gehemmt. Das Übersetzen der Geschütze erwies sich als sehr zeitraubend. Währenddessen gab es durch die Befragung der Zivilbevölkerung erste Gerüchte, dass es bei Maxen nicht sonderlich gegangen; BRABANT, Kesselsdorf und Maxen (wie Anm. 3), S. 194; Generalstab, Minden und Maxen (wie Anm. 3), S. 218.

56 Bericht des Generalquartiermeisters von Zeutzsch an Rutowski vom 30. September 1756; Befehl Rutowskis an Zeutzsch vom 1.10.1756; von SALIsch, Treue Deserteure (wie Anm. 1), S. 92-94, 96, 106-110. Interessant ist in diesem Zusammenhang der Aktenbestand Sächsisches Staatsarchiv - Hauptstaatsarchiv Dresden, Loc. 10989, Concepte von Ordres an den Herrn Generalmajor und Geheimen Kriegsrath von Zeutzsch 1756.

57 Tagebuch eines Preußischen Offiziers (wie Anm. 12), S. 336 f. 
Zahn notierte: Auf die letzte hatten wir kein Blatt, keinen Strunk, keinen Holzapfel nicht, da war gar kein Bleiben nicht mebr. ${ }^{58}$ Es erscheint angesichts dieser Lageentwicklung nachvollziehbar, dass sich die sächsische Führung mit steigendem Nachdruck um wirksame Unterstützung durch die österreichische Armee bemühte. War man auch in Wien vom preußischen Überfall überrascht, so hatte Maria Theresia dem sächsischen Kurfürsten dennoch ihre Unterstützung zugesagt. Am 14. September, als der Entsatz des sächsischen Heeres bereits „eine Aufgabe für Armeen" ${ }^{59}$ geworden war, brach Feldmarschall Maximilian Ulysses Graf Browne (1705-1757) mit seinen in Nordböhmen zusammengezogenen Truppen auf und erreichte am 30. September die Gegend um Lobositz. ${ }^{60} \mathrm{Bis} \mathrm{zu}$ diesem Zeitpunkt gelang es dem sächsischen Hauptquartier noch, Boten durch die preußische Umschließung zu schicken und einen Plan für den Ausbruch zu verabreden. ${ }^{61}$ Die österreichischen Truppen wurden von Friedrich II. jedoch gleich zwei Mal zurückgewiesen: Einmal in der erwähnten Schlacht bei Lobositz (1. Oktober 1756), als sich Friedrich II. dem österreichischen Feldmarschall mit dem Gros seiner Truppen entgegenstellte. ${ }^{62}$ Zum zweiten Male, als Browne sich

58 Zitiert nach Stefan Kroll, Kursächsische Soldaten in den drei Schlesischen Kriegen, in: Dresdner Hefte 68 (2001), S. 40.

59 Christopher Duffy, Feldmarschall Browne. Irischer Emigrant, Kaiserlicher Heerführer, Gegenspieler Friedrichs II. von Preußen, Wien 1966, S. 279.

60 Minister Brühl lieferte ihm nur eine sehr grobe Beschreibung eines möglichen Anmarschweges. Kartenmaterial war offenbar nicht vorhanden, was in dieser Zeit aber keineswegs ungewöhnlich war; von Salisch, Treue Deserteure (wie Anm. 1), S. 100; zum Stand der Kartografie während des Siebenjährigen Krieges exemplarisch: EwA AnkLam, Wissen nach Augenmaß. Militärische Beobachtung und Berichterstattung im Siebenjährigen Krieg (Herrschaft und soziale Systeme in der Frühen Neuzeit 10), Berlin 2007, S. 58-66; Johann GotTlieb Tielke, Unterricht für die Officiers, die sich zu FeldIngenieurs bilden, oder doch den Feldzügen mit Nutzen beywohnen wollen, durch Beyspiele aus dem letzten Kriege erläutert und mit nöthigen Plans versehen, Dresden 1769.

61 Der Kurfürst und Graf Brühl favorisierten einen Brückenschlag über die Elbe, die Generalität äußerte sich in einem Kriegsrat angesichts der geografischen Hindernisse eher skeptisch: Eine Brücke unter dem Königstein zu schlagen sey zwar nicht unmöglich; man möchte aber bedenken, daß die gefährlichen Wege, welche zur Elbe herunter fübrten; die Zeit, die zum Uebergange auf einer einzigen Brücke erfordert würde; die Beschwerlichkeit, das Geschütz auf die jenseitigen steilen Felsen hinauf zu ziehen; der sebr beschränkte Raum, den die sogenannte Ebenheit ibnen zu ibrer Bewegung verstatte; die Stärke der preußischen Verschanzungen oder Verhaue, so wie die engen Pässe, wo ein einziges Bataillon mit einigen Feldstücken im Stande sey, eine Armee aufzubalten eben so viele erbebliche Hindernisse wären, deren man bei einer nur schwachen Hoffnung, Eins oder das Andere gehoben zu seben, gewärtigen müssen.; zitiert nach Bode, 1756. Der Beginn des Siebenjährigen Krieges (wie Anm. 1), S. 28; vON SAlisch, Treue Deserteure (wie Anm. 1), S. 77, 87, 98-103.

62 Friedrich II. marschierte mit etwa 30.000 Mann in die Schlacht bei Lobositz und ließ ca. 11.000 Mann bei Pirna zurück. Durch Täuschungsmaßnahmen suggerierte die preuBische Armee jedoch ihre volle Stärke. Angeblich soll man im sächsischen Hauptquartier vom Abmarsch preußischer Truppen gewusst haben. Das wirkliche Lagebild Rutowskis ist für diese Zeit aber nur schwer zu rekonstruieren. Da die sächsische Armee über längere Zeit keine gesicherte Information über den Ausgang der Schlacht bei Lobositz 
wenige Tage später nochmals mit einem „fliegenden“ Korps durch die Berge des Elbsandsteingebirges - ein für damalige Verhältnisse außergewöhnliches Unternehmen ${ }^{63}$ - dem sächsischen Lager zu nähern versuchte. Für das österreichische Korps war der Anmarsch durch das unwegsame Elbsandsteingebirge äußerst strapaziös. So konnte Browne nur etwa bis Bad Schandau vordringen, denn er wurde von den preußischen Belagerungstruppen, die sich zwischen die sächsische Armee und sein Korps geschoben hatten, aufgehalten. ${ }^{64}$ Den eingeschlossenen Truppen konnte er deshalb ebenso wenig Unterstützung bieten, wie General Fink Hilfe von den preußischen Entsatztruppen erwarten konnte.

\section{Der Ausbruchsversuch}

Zunächst gilt es noch einmal festzuhalten, dass in Pirna und in Maxen die Kampfhandlungen jeweils von schlechtem Wetter begleitet wurden: in Pirna Regen und Nebel, in Maxen vor allem Schnee und Frost. Dies zehrte an den Kräften von Mensch und Tier, erschwerte die Aufklärung des Feindes und machte bei der sächsischen Armee das Schießpulver größtenteils unbrauchbar. Die Vorbereitungen zum Ausbruch mussten in beiden Fällen zudem in unmittelbarer Nähe zum Feind, unter großem Zeitdruck und unter weiteren Erschwernissen, nämlich nachts, geschehen. Solche Umstände führen erfahrungsgemäß immer zu Verwirrungen, welche ein solches Unternehmen wiederum verzögern. Dabei handelten die beiden maßgeblichen Heerführer keineswegs eigenständig, sondern versuchten, in Anbetracht der Tragweite des Kommenden ihre Entscheidung auf eine möglichst breite Basis zu stellen. Sowohl General Fink als auch Feldmarschall Rutowski hielten Kriegsräte ab; die sächsische Generalität besprach sich sogar mehrfach. ${ }^{65}$ Fink beriet sich in der Nacht vom 20. zum 21. November 1759 mit seinen Generälen. Hierbei sollen verschiedene Möglichkeiten zum Ausbruch betrachtet worden sein. Offenbar hatte der um seine Ehre und Reputation bedachte Fink zunächst tatsächlich die Absicht, seine verbliebenen Truppen, die durch das Erlebte

besaß, barg ein Ausbruch zu diesem Zeitpunkt offenbar zu viele Risiken; von SALIsch, Treue Deserteure (wie Anm. 1), S. 101 f., 105 f. Zur propagandistischen Auseinandersetzung zwischen den Kriegsparteien über den „Sieg“ bei Lobositz: BERNHARD JaHn, Die Medialität des Krieges. Zum Problem der Darstellbarkeit von Schlachten am Beispiel der Schlacht bei Lobositz (1. Oktober 1756) im Siebenjährigen Krieg, in: Wolfgang Adam/Holger Dainat (Hg.), „Krieg ist mein Lied“. Der Siebenjährige Krieg in den zeitgenössischen Medien, Göttingen 2007, S. 92-94.

63 Duffy, Browne (wie Anm. 59), S. 302 f.

64 Ebd., S. 302-309, Schreiben Brownes an Franz Stephan vom 14. Oktober 1756; zitiert nach ebd., S. 306. Zur Schlacht bei Lobositz: Duffy, Friedrich (wie Anm. 1), S. 150-159; Kunisch, Friedrich (wie Anm. 5), S. 351 f.

65 Am 10. September beschloss die sächsische Generalität in der Hoffnung auf baldigen Entsatz das Verbleiben bei Pirna. Weitere Kriegsräte folgten nach dem Misslingen des Ausbruchsversuches am 13. und 14. Oktober; von Salisch, Treue Deserteure (wie Anm. 1), S. 87 f., 121, 123. 
und die herrschende Witterung erschöpft und demotiviert waren, in einem verzweifelten Ausbruchsversuch gänzlich zu opfern und ließ bereits entsprechende Vorbereitungen treffen. Dies hätte dem Ehrverständnis eines preußischen Generals, der zum "Contenance Halten“ erzogen war, entsprochen. Gerade dieser „Point d'honneur“, die Anforderungen an die Generalität und ihre „Leistungspflicht" waren in der preußischen Armee sicher besonders ausgeprägt.66 Die genauere Feststellung der aktuellen Stärke seines Korps war jedoch ernüchternd und begrub alle Erfolgsaussichten: Weniger als 7.000 Mann, drei Kanonen und wenig Munition standen Fink noch zur Verfügung. ${ }^{67}$ Erkundungen ergaben zudem, dass alle möglichen Ausgänge durch gegnerische Truppen besetzt waren. Angesichts dieser Situation herrschte Ratlosigkeit im Hauptquartier. Es wurde einzig beschlossen, die Kavallerie sollte unter Führung des Generals Johann Jakob von Wunsch (1717-1788) versuchen, noch unbemerkt durch die feindlichen Truppen zu gelangen. ${ }^{68}$ Ansonsten sah Fink nur eine Möglichkeit, seinem König zumindest die Truppen zu erhalten: Kapitulation. Neben der Hoffnung auf freien Abzug spekulierte er darauf - und dies war unter damaligen Verhältnissen nicht unrealistisch -, dass es im schlimmsten Falle binnen kurzer Zeit zu einem der üblichen Gefangenenaustausche zwischen den verfeindeten Heeren kommen würde. ${ }^{9}$ Dass

66 Die Verantwortlichkeit der Generäle und ihre „Leistungspflicht“ betrafen weniger den Erfolg oder Misserfolg einer militärischen Aktion, sondern vielmehr die Art und Weise der Durchführung des Auftrages. Justitiabel wurde „ungenügende“ Leistung vor allem wegen der Frage nach der moralischen Wirkung auf die Armee; LoTz, Kriegsgerichtsprozesse (wie Anm. 3), S. 79-83; Duffy, Friedrich (wie Anm. 1), S. 281 f.

67 Eine genaue Analyse der Stärkeangaben findet sich bei Mollwo, Die Kapitulation (wie Anm. 3), S. 16, 73.

68 Dieses von Wunsch selbst vorgeschlagene Unternehmen wurde zwar versucht, es scheiterte aber letztendlich. Auf österreichischer Seite bestand man darauf, dass sich auch die unter Finks Befehl stehende Kavallerie mit in Gefangenschaft zu begeben habe. Andernfalls drohte man mit einer Fortsetzung der Gefechtshandlungen. Fink ließ Wunsch daraufhin umkehren; Mollwo, Die Kapitulation (wie Anm. 3), S. 74-77.

69 Im 18. Jahrhundert war ein zwischenstaatliches Kriegsrecht noch nicht kodifiziert. Dennoch herrschte ein durchaus verbindliches „Gewohnheitsrecht“ vor. Hierzu gehörte auch die Auswechslung von Kriegsgefangenen, zu deren Zweck Einzelkonventionen geschlossen wurden. Dies zeigt die Wertigkeit der aufwendig rekrutierten und ausgebildeten Soldaten für den jeweiligen Kriegsherrn. Zudem verursachten der Unterhalt sowie die Bewachung von Kriegsgefangenen unliebsame Kosten. Als „Kriegsgefangene“ galten im zeitgenössischen Verständnis Personen, „die sich entweder freiwillig, um ihr Leben zu erhalten, dem Feind ergeben, oder wider ihren Willen, wenn sie außer Stand gesetzt werden, sich zu wehren, in die Gewalt derselben kommen." „Nichtkombattanten“ wie Marketender, Handwerker, Feldgeistliche, Soldatenfrauen und -kinder waren von der Gefangennahme ausgeschlossen. Die Gefangenen wurden zunächst durch einen Auditeur in Listen erfasst; diese konnten dann zwischen den Krieg führenden Parteien ausgetauscht werden. Zwischen Preußen und Österreich wurde 1741 das Kartell von Grotkau zur Auswechslung von Gefangenen geschlossen und 1756 verlängert. Hierbei wurden auch die Geldwerte der Soldaten festgelegt: für den „gemeinen Mann“ bis zum Sergeanten fünf Gulden; 15.000 Gulden hingegen für einen Generalfeldmarschall. Mit dem Wandel vom Söldnerwesen zum miles perpetuus erlangte jedoch der Austausch „Mann gegen Mann“ zunehmende Bedeutung. Im Früh- 
es in der Folge diesen Austausch wider Erwarten nicht gab, kann als Verschärfung des Konfliktes gedeutet werden: Man entzog dem ohnehin an Humanressourcen Mangel leidenden Staat Preußen das militärische Personal. Im Grundsatz entsprach dies der Gesamtstrategie der antipreußischen Koalition, welche in diesem Konflikt von Beginn an auf den „l̈̈ngeren Atem“ setzte. ${ }^{70}$ Letztendlich hatte der Kriegsrat zum Ergebnis, dass Verhandlungen mit den österreichischen Truppen aufgenommen wurden. Es erschien der preußischen Generalität offenbar wichtig, diese noch vor Tagesanbruch zu beginnen, um die Schwäche der eigenen Truppen vor dem Gegner verbergen zu können. Kurz vor Tagesanbruch wurde General Johann Karl Freiherr von Rebentisch (1710-1765), der früher in österreichischen Diensten gestanden hatte, mit der Überbringung des Kapitulationsangebotes beauftragt. Er hatte sich während des Kriegsrates wohl für eine Waffenstreckung ausgesprochen, während sich die übrige Generalität offenbar zurückhielt.71 Tatsächlich konnte niemand eine Mittelstraße zwischen dem Gefangennehmen und der Aufopferung des gesamten Korps entdecken. ${ }^{72}$ Die Verhandlungen fanden anschließend im preußischen Hauptquartier zwischen Fink und dem österreichischen General Moritz Graf von Lascy (1725-1801) statt. Dass sich die Offiziere beider Armeen zur Begrüßung herzten und küssten, mag ebenso Bestandteil einer Armeen übergreifenden Offiziers- beziehungsweise Adelskultur gewesen sein wie das spätere gemeinsame Mahl der preußischen beziehungsweise sächsischen Generalität mit dem jeweiligen siegreichen Feldherrn. ${ }^{73}$ Es täuschte jedoch nicht über den Ernst der Lage hinweg: Das Schicksal des Restes von Finks Korps lag nun in den Händen des österreichischen Feldmarschalls Daun. Um die Moral des

jahr 1759 kam es beispielsweise zu einem Austausch von 18.494 preußischen Soldaten - aus diesen hätten immerhin elf neue Regimenter formiert werden können. Das österreichische Reglement zeichnete sich hinsichtlich des Umganges mit Gefangenen durch eine humanere Grundhaltung aus als das preußische. Auch Feldmarschall von Schwerin äußerte in seinen „Gedanken über einige militairische Gegenstände“, dass auf die Versorgung der Gefangenen im preußischen Heer mebr Attention zu legen sei. Eine schlechte Behandlung derselben führe nur zur Verbitterung in denen Truppen gegeneinander. Es soll General Fink bei Maxen bekannt gewesen sein, dass sich gleichzeitig zahlreiche österreichische Offiziere in preußischem Gewahrsam befanden; VoIGTLÄNDER, Die preußischen Kriegsgefangenen (wie Anm. 49), S. 7 f., 12-19; KeEGAN, Das Antlitz des Krieges (wie Anm. 46), S. 382 f.; Generalstab, Minden und Maxen (wie Anm. 3), S. 221; Kroll, Soldaten im 18. Jahrhundert (wie Anm. 1), S. 435-453; Des Königlich preußischen Feldmarschalls Grafen von Schwerin Gedanken über einige militairische Gegenstände, in: Krise, Reformen - und Militär (wie Anm. 24), S. 156.

70 Vgl. Kunisch, Friedrich (wie Anm. 5), S. 336-338; Kroener, Wirtschaft und Rüstung der europäischen Großmächte im Siebenjährigen Krieg (wie Anm. 31).

71 Friedrich II. soll Rebentisch wiederholt mit Misstrauen begegnet sein. Später wurde er beschuldigt, Fink beim Entschluss zur Waffenstreckung beeinflusst zu haben; BRABANT, Kesselsdorf und Maxen (wie Anm. 3), S. 183; Allgemeine Deutsche Biographie, Bd. 26, Leipzig 1888, S. 479 f.

72 Journal, von dem Finckischen Corps (wie Anm. 42), S. 606.

73 Ein weiteres Zeichen für das eigene Standesbewusstsein des Offizierkorps war beispielsweise das Zusammentreffen von Offizieren eigentlich verfeindeter Parteien während der Kuraufenthalte außerhalb der Feldzüge; von SALISCH, Treue Deserteure (wie Anm. 1), S. 55, 57. 
Gegners vollends zu brechen, hatten dessen Truppen vor Beginn der Verhandlungen das Feuer noch einmal kurz eröffnet - eine Demonstration der Stärke, die bereits überflüssig war. ${ }^{74}$

Sie haben nun meine ganze Stellung gesehen; machen Sie davon dem Grafen [Brühl, Anm.] eine genaue Beschreibung, und sagen Sie ibm: ich überließe es seiner eigenen Beurtheilung, ob er sich noch getraue, sich durchzuschlagen. ${ }^{75}$ Mit diesen Worten besiegelte der preußische General Hans Karl von Winterfeldt (1707-1757) am 14. Oktober 1756 in einer Unterredung mit Rutowski das Schicksal der sächsischen Truppen. Vorangegangen war ein spektakulärer Ausbruchsversuch: Der Hunger und das Fehlen jedweder Nachricht von Feldmarschall Browne bewegten die sächsische Generalität dazu, den Ausbruch unterhalb des Königsteins mittels eines Brückenschlages über die Elbe zu wagen. Das Heer präparierte sich dazu nicht nur in organisatorischer, sondern auch in mentaler Hinsicht, wie die Überlieferung von einer letzten Betstunde belegt. ${ }^{76}$ Allerdings konnten die umfangreichen Vorbereitungsmaßnahmen kaum geheim gehalten werden. Als die preußische Artillerie versuchte, die Brückenteile im Voraus zu versenken, kam es zur offiziellen Eröffnung der Kampfhandlungen. Analog zu Maxen konnte also auch in diesem Falle kein „überraschender“ Ausbruch mehr erfolgen. Dennoch brach die sächsische Armee am Abend des 12. Oktober 1756 in aller Stille aus ihrem Lager auf und marschierte zur Brücke. Durch Dunkelheit, schlechte Wegeverhältnisse und die Flucht ziviler Fuhrknechte erreichten Spitzen des Heeres erst gegen Mitternacht die Brücke. Ein Bericht gibt die Strapazen des Übergangs wieder: Ehe 7 Bat. Grenadiers sich dißeit des Liliensteins in Scblacht-Ordnung zu stellen vermochten, war es schon halben Tag und diese hatten auch nur 2 Canonen bey sich, alle übrigen waren in dem einzigen Wege, wo die Wagens fabren können, stecken geblieben. [...] Allein diese [die Armee, Anm.] war so wenig versammlet, daß die Cavallerie escadronweise mit der Artillerie vermengt, die ganze Nacht vom 13. zum 14. am Ufer der Elbe zubringen mußte und überdieß das Fener-Gewehr, wegen deß bäuffigen und den ganzen Tag dauernden Regens nicht zu gebrauchen war. ${ }^{77}$ Die Sachsen, die bis zum Tagesanbruch das andere Ufer erklommen hatten,

74 Der Verlust der österreichischen Truppen wird mit 934 Toten und Verwundeten angegeben; Mollwo, Die Kapitulation (wie Anm. 3), S. 74 f.; Brabant, Kesselsdorf und Maxen (wie Anm. 3), S. 183-188; Generalstab, Minden und Maxen (wie Anm. 3), S. $210 \mathrm{f}$.

75 Hervorzuheben ist hierbei, dass man auf preußischer Seite die Entscheidung nicht vom sächsischen Kurfürsten, sondern von Graf Brühl erwartete.

76 Hierbei wurde auch das Gerücht verbreitet, dass der im Heer sehr verehrte Kurfürst an der Spitze der Truppen stehen werde, was im Nachhinein nicht den Tatsachen entsprach; von Salisch, Treue Deserteure (wie Anm. 1), S. 114 f.; siehe auch Stefan Kroll, „Gottesfurcht“ und „Vaterlandsliebe“: Zwei Triebfedern zur Motivierung und Disziplinierung im Krieg? Das Beispiel Kursachsen im 18. Jahrhundert, in: Michael Kaiser/ Stefan Kroll (Hg.), Militär und Religiosität in der Frühen Neuzeit (Herrschaft und soziale Systeme in der Frühen Neuzeit 4), Münster 2004, S. 225-248.

77 Kurze und gegründete Nachricht von dem Auszug der Kgl. Chursächsischen Armee aus dem Laager bey Pirna (anonym); zitiert nach von SaLISCH, Treue Deserteure (wie Anm. 1), S. 117. 
fanden jedoch nicht die erwarteten Österreicher vor, sondern derart starke preuBische Verschanzungen, dass sich jeder Angriff auf dieselben verbot. Zudem rückten inzwischen die preußischen Truppen auf das Terrain des verlassenen Lagers vor und griffen die noch nicht übergesetzte sächsische Nachhut an. An der Schiffbrücke kam es daraufhin zu dramatischen Szenen. Beim eiligen Versuch, die Brücke einzuschwenken, riss diese gänzlich ab. Damit war das sächsische Heer in die nächste Einschließung geraten. Da auch jegliche Anzeichen einer Annäherung von Feldmarschall Browne fehlten, war der Beschluss des Kriegsrates offenbar einhellig und alle Generals, obne Ausnabme, bielten dafür, daß in einem solchen Unternebmen das Volck lediglich auf die Schlachtbank würde gefübret werden..$^{78} \mathrm{Der}$ Kurfürst, den man auf den Königstein in Sicherheit gebracht hatte, teilte diese Ansicht zunächst nicht: Er forderte seine Truppen im Vertrauen auf die Vorsebung zum Angriff auf! In dieser Lage trat Rutowski am 14. Oktober eigenmächtig in Verhandlungen mit der preußischen Seite. Ein zweiter Kriegsrat gelangte daraufhin zum Ergebnis: Wir haben uns gegen ein Corps, weit stärker als das unsere, gebalten, täglich des Angriffs gewärtig, haben wir den Feind bisher während dieser ganzen Zeit aufgehalten. [...] Die Unglücksfälle, die uns in diese Lage gebracht haben, konnten weder vorhergesehen, noch überwunden werden. An dem Könige ist es zu sprechen. Die Armee wird ibr Blut hergeben, aber vergeblich. Ihre Vernichtung, welche unvermeidlich, könnte weder die Waffenebre, noch den Staat retten und würde ein Corps von Generalen, welche bisher in Ehren und in Trene gedient zu haben glauben, dem gerechten Vorwurfe der Unwissenheit und Verwegenheit aussetzen. ${ }^{79}$ Es bedurfte jedoch noch der mehrfachen Vorstellung der Aussichtslosigkeit der Lage, bis der Kurfürst mit dem Ausdruck seiner äußersten Bekümmerni $\beta$ das Schicksal seiner Armee in die Hände der Generalität legte: Daß euer Kriegs-Rath einen Schluss fasse, ob ibr euch kriegsgefangen [!] ergeben oder ob ibr durchs Schwert und Hunger umkommen wollt. [...] Ich habe nichts damit zu thun und daß wir nichts, als die so einzige Sache, die Waffen nicht wider uns und unsere Freunde zu fübren, zu Eurer Verantwortung ausstellen werden, schrieb er an Rutowski. ${ }^{80}$ Dieser besaß somit vergleichbare „Freiheiten“ wie Fink: Tod oder Kapitulation.

78 Ebd., S. 121.

79 Schreiben der sächsischen Generalität an den Kurfürsten vom 14. Oktober 1756; zitiert nach Carl F. Vitzthum von Eскstädt, Die Geheimnisse des sächsischen Cabinets. Ende 1745 bis Ende 1756, Teil 2, Stuttgart 1866, S. 222 f.

80 Schreiben an Rutowski vom 14. Oktober 1756. Entsprechend lautete auch der erste und der dritte Punkt des sächsischen Entwurfes der Kapitulationsurkunde vom 15. Oktober: 1. Die Königl. Poln. und Churfürstl. Sächs. Armée, wie sich solche dermahlen allhier in dem Posten Ebenheit unter dem Lilienstein befindet [...] ergiebt sich an Ibro Königl. Majestät in Preußen als Kriegs-Gefangene. [...] 3. Ibro Königl. Majestät geruhen allergnädigst die Armée mit Vivres und Fourage des fördersamst verseben zu lassen, und darüber Dero gemessenste Ordres zu stellen; zitiert nach von SALIsch, Treue Deserteure (wie Anm. 1), S. 125 f. 


\section{IV. „Das Ereignis hat das ganze Kriegstheater verändert... “ Die Kapitulation}

Am Morgen des 17. Oktober bildeten die preußischen Einheiten ein Spalier, durch das die sächsische Armee ausmarschierte, um anschließend in einen offenen Kreis aus preußischen Soldaten einzurücken. Die Zeremonie der Waffenstreckung ist durch Rutowski gut überliefert: Nachdem der grösste Theil der Infanterie [...] die Schiffbrü̈ke bei Oberrathen passirt, hat man Preussischer Seits successive, um jedes Regiment, nachdem man alle Stabs- und Oberoffiziere davon abgesondert, einen Kreis schliessen und dabei diese List gebrauchen lassen, als wenn Ew. Königl. Majestät an des Königs von Preussen Majestät Dero Truppen in Dero Dienste überlassen hätten und sie also dem König von Preussen getreu zu sein schwören sollten [...] dadurch dann der gemeine Mann, ob man gleich die Vorsicht im Voraus angewendet, ibn durch Offiziere avertiren zu lassen, dass er zwar kriegsgefangen wäre, jedoch nicht gezwungen werden könnte, Dienst zu nebmen, dennoch zum Theil den falschen Vorwand gebrauchte, dass die abgesonderten Offiziere bereits den Eid abgeleget, übereilet worden, zum Theil nicht gewusst, was er thäte. Wie dann von denen im Kreise befindlichen und sich melirten Preussen mebr als von den Kriegsgefangenen da Ja geantwortet und Vivat ausgeschrieen worden, auch man sich um die protestationes derjenigen Mannschaft, so gar nicht schwören und Dienst nebmen wollen, im Geringsten nicht gekehrt hat. ${ }^{81}$ Die Preußen bildeten demnach eine bedrohliche Kulisse, separierten die Offiziere und zwangen die sächsischen Mannschaften und Unteroffiziere entgegen allen Erwartungen mit List, Drohungen und Spott zur Ableistung des preußischen Kriegseides - eine zu dieser Zeit außergewöhnliche Maßnahme, die eher an den Kriegsbrauch der Landsknechte erinnert. ${ }^{82}$ Die Waffenstreckung bildete nicht nur für die auf ihre Ehre bedachten Offiziere ein einschneidendes Erlebnis. Auch der einfache sächsische Soldat, der während der Belagerung sehr loyal zu seiner militärischen Gemeinschaft gehalten hatte, ${ }^{83}$ war hiervon persönlich tief getroffen. Durch

81 Eine ähnliche Beschreibung findet sich bei: Tagebuch eines Preußischen Offiziers (wie Anm. 12), S. 343-347.

82 Kunisch, Friedrich (wie Anm. 5), S. 353; vgl. Ernst Höfer, Das Ende des DreiBigjährigen Krieges. Strategie und Kriegsbild, Köln 1997, S. 167 f.

83 Bis zur Schlacht bei Lobositz hatten kaum mehr als 70 sächsische Soldaten Fahnenflucht begangen. Auch sind nur wenige Verstöße gegen die Disziplin überliefert. Dies ist umso ungewöhnlicher, da gerade bei belagerten Truppen die Desertion häufig stark anstieg. Untätigkeit, Versorgungsschwierigkeiten und Ungewissheit führten in solchen Situation oft dazu, dass sich die Soldaten vermehrt von ihren Regimentern entfernten. Andererseits ermöglichte die „statische“ Kriegführung bei einer Belagerung auch eine gute Kontrolle über die eigenen Truppen. Feldmarschall Rutowski erließ beispielsweise am 6. Oktober einen Armeebefehl, der den Wachen Belohnungen versprach, wenn diese Deserteure an der Flucht hindern sollten. Die Standhaftigkeit der sächsischen Soldaten ist auch durch preußische Quellen überliefert. Sie deutet auf ungewöhnlich verfestigte Strukturen im sächsischen Heer hin. Die „Kameradschaft“ des Zeltes - Wohn-, Arbeits-, Kampf- und damit Überlebensgemeinschaft zugleich - erfüllte ihren integrativen Zweck offenbar in hohem Maße. Einen großen Anteil daran hatten nicht zuletzt die Unteroffizierdienstgrade, die als „Korsettstangen“ ihre Kleingruppen auch 
wochenlange Entbehrungen und durch das Wechselspiel von Endlosigkeit und Hoffnung bereits stark angegriffen, muss die letztendliche Niederlage umso stärker gewirkt haben: Da schmissen wir alles weg und mußten das Gewebr strecken, da hatte keiner weder Mut noch Sinn. Das ließ erbärmlich, notierte der Infanterist Gottfried Zahn. ${ }^{84}$

Eine vergleichende Betrachtung mit der Kapitulationszeremonie bei Maxen lässt wiederum Rückschlüsse hinsichtlich einer ungeschriebenen, aber dennoch verbindlichen „Kapitulationskultur“ innerhalb der Armeen des 18. Jahrhunderts $\mathrm{zu}$, auf feste Rituale im Umgang mit dem besiegten Gegner. Durch eine abermalige Demonstration der Stärke bestätigten sie den Sieger in seiner Rolle, sie überantworteten das unterlegene Heer in dessen Hände und besiegelten die Niederlage somit feierlich. Auch im Falle der Waffenstreckung bei Maxen ist nach dem Bericht des preußischen Musketiers Dominicus vom Infanterieregiment Nr. 9 „von Schenckendorff“ von einem Karree die Rede: Wir mußten antreten. Da wurde uns gesagt, dass wir gefangen wären [...] Gewebr und Tasche Säbel müßten wir ablegen. Indem kommandierte Major Iselstein: „Gebt Achtunge! Streckt das Gewebr!" Wir wurfens hin und da Tasche und Säbel drauf. [...] Wie das vorbei mußten wir rechtsum machen, und da hatten die Österreicher ein Karree formiert, da trieben sie uns hinein. Da waren die Österreicher frob und lachten uns aus. ${ }^{85}$ Später nochmals Ähnliches in Budweis: Den 9. [Januar 1760, Anm.] musten wir alle aufs Markt ausrücken, wurde ein Kreis geschlossen, war ein Östreicher Kommissarius, laß uns vor: diejenigen, welche Östreich Saksen Schweden Russen

später beisammen hielten. Als weitere Faktoren sind hier nur exemplarisch die Anwesenheit des verehrten „Landesvaters“, die religiöse Homogenität sowie die hohe landsmannschaftliche Geschlossenheit zu nennen; vON SALISCH, Treue Deserteure (wie Anm. 1), S. 50, 61, 102, 135, 152 f., 194 f.; JöRg Muth, Flucht aus dem militärischen Alltag. Ursachen und individuelle Ausprägung der Desertion in der Armee Friedrichs des Großen (Einzelschriften zur Militärgeschichte 42), Freiburg i. Br. 2003, S. 103; zur frühneuzeitlichen „Lagergesellschaft“ siehe auch BERnHARD R. KROENER, „...und ist der jammer nit zu beschreiben“. Geschlechterbeziehungen und Überlebensstrategien in der Lagergesellschaft des Dreißigjährigen Krieges, in: Kriegerische Gewalt und militärische Präsenz (wie Anm. 31), S. 115-119.

84 Zitiert nach Kroll, Kursächsische Soldaten (wie Anm. 58), S. 40. Vor dem Hintergrund der extremen Disziplinierung der Soldaten des 18. Jahrhunderts durch den „Drill“ kann das geschilderte Wegwerfen der Ausrüstung (und ggf. auch des Gewehrs) durch die Infanteristen als ein Ausdruck hoher emotionaler Aufgeladenheit gewertet werden. Auch von der Kapitulation bei Yorktown 1781 ist überliefert, dass einige Engländer ihre Waffen aus Wut auf den Boden geknallt hätten; BARTHOLD KOCH, Kurze Kriegsgeschichte des siebenjährigen deutschen, des achtjährigen englisch-amerikanischen, der Begebenheiten zwischen Hessen und Bückeburg nebst anderen Vorfällen in Hessen und zuletzt des französisch-deutsch-russischen Krieges (Hessische Forschungen zur geschichtlichen Landes- und Volkskunde 43), hrsg. u. komm. von Uwe-Peter Boehm/ Reinhard G. Koch, Kassel 2007, S. 90; Keegan, Das Antlitz des Krieges (wie Anm. 46), S. $361 \mathrm{f}$.

85 Auch die Zivilbevölkerung begegnete den gefangenen Preußen mit Spott; KerLer, Tagebuch des Musketiers Dominicus (wie Anm. 44), S. 77 f. 
gedientt, sollten und müsten sich melden. Es wurde ibnen völligen Pardon versprochen. ${ }^{86}$ Ein ähnliches Vorgehen ist interessanterweise auch aus dem Amerikanischen Unabhängigkeitskrieg überliefert. ${ }^{87} \mathrm{Im}$ Gegensatz zum sächsischen Heer mussten Finks Truppen bei Maxen auch alle "gehabten Fahnen, Standarten, Pauken, Trompeten und übrigen Kriegszeichen“ übergeben. In Anbetracht der Bedeutung von Feldzeichen für die Reputation eines militärischen Verbandes war dies ein niederschmetterndes Ereignis. ${ }^{88}$ Daran änderte auch der Umstand nichts, dass die Kapitulation sowohl in Maxen als auch bei Pirna nicht schriftlich fixiert wurde, demnach also keine unterzeichneten Kapitulationsurkunden existieren.

86 Ebd., S. 80.

87 Von General Cornwallis Kapitulation bei Yorktown im Jahre 1781 wird berichtet: Wir marschierten [...] in Zügen mit geschultertem Gewehr durch die ganze feindliche Armee durch [...] rechts auf einen ebenen Platz oder eine große Haide, wo ein Schwadron französischer Husaren einen Kreis geschlossen hatte. Zu diesem Kreis marschierte ein Regiment nach dem anderen, streckte das Gewebr und legte alle Waffen ab.; zitiert nach Daniel Krebs, The Making of Prisoners of War, in: Militärgeschichtliche Zeitschrift 64 (2005), S. 1 f., 7 f. Vgl. hierzu auch: Косн, Kurze Kriegsgeschichte (wie Anm. 84), S. $90 \mathrm{f}$. Wünschenswert sind weitere diachrone Untersuchungen zum Thema „Kapitulationskultur", insbesondere zu den Zeit überdauernden und sich wandelnden Bestandteilen dieser militärischen Zeremonie. Beispielsweise ist überliefert, dass es bereits bei Feldzügen im 4. Jh. n. Chr. zu Waffenstreckungen kam, in deren Verlauf die Unterlegenen niederknieten und dabei von einem „waffenblitzenden Ring“ beziehungsweise einem "Spalier“ aus Soldaten umgeben waren. Der französische Schlachtenmaler Edouard Dettaile (1848-1912) stellt in seinem Gemälde „La reddition du général Baron Barbanègre à Huningue le 27 aout 1815“ (Öl auf Leinwand, 1892) ebenfalls den Abzug der französischen Truppen durch ein Spalier österreichischer Soldaten unter Erzherzog Johann dar. Ettighofer erwähnt in seinen Ausführungen zur Übergabe der Panzerfeste Vaux 1916 ebenfalls eine Art „Ehrenspalier“ für die abziehende französische Besatzung. Auch für die verhaftete Regierung Dönitz bildeten US-Soldaten 1945 ein bedrohliches Spalier; Christian Pantle, Die Varusschlacht. Der germanische Freiheitskrieg, Berlin 2009, S. 113; Paul C. Ettighofer, Verdun. Das große Gericht, Gütersloh 1936, S. 244 f.; "Es ging nicht anders“. Wie Hitlers Nachfolger Karl Dönitz versuchte, den Geist der NS-Zeit über die Stunde Null hinwegzuretten, in: Der Spiegel, Jg. 1995, Nr. 19, S. 85.

88 Übergeben wurden 96 Fahnen, 24 Standarten, vier Paar Pauken, zudem die gesamte Artillerie und die Pferde der Kavallerie (etwa 3.000). Die erbeuteten Geschütze wurden am nächsten Tag in Dresden als „Trophäen“ zur Schau gestellt. Zahlreiche der weggeworfenen Waffen, Ausrüstungsgegenstände und Pferde sollen nach der Kapitulation von der Zivilbevölkerung und von „Handelsjuden“ verkauft worden sein. Der Überlieferung zufolge soll das Dragonerregiment „von Platen“ seine Standarte vergraben haben, um diese nicht in die Hände des Feindes gelangen zu lassen. Die Beibehaltung der „Bagage“ wurde dem Finkschen Korps jedoch gewährt, was zu den üblichen Gepflogenheiten zählte, Tielke, Das Treffen bey Maxen (wie Anm. 3), S. 33; Generalstab, Minden und Maxen (wie Anm. 3), S. 210 f.; Brabant, Kesselsdorf und Maxen (wie Anm. 3), S. 190, 196. Zur Bedeutung von Feldzeichen siehe auch: KeEgAn, Das Antlitz des Krieges (wie Anm. 46), S. 216 f. Der Abzug mit eingerollten Fahnen galt im 18. Jahrhundert beispielsweise als ehrenrührig; KосH, Kurze Kriegsgeschichte (wie Anm. 84), S. 90, 124. Den sächsischen Regimentern wurden zum Vergleich 1756 die Pauken und Feldzeichen belassen. Dies war eines der wenigen Zugeständnisse Friedrichs II. an das sächsische Heer. Die Feldzeichen wurden für die Dauer des Krieges auf der Festung Königstein aufbewahrt; von SAlisch, Treue Deserteure (wie Anm. 1), S. 130, 281. 


\section{Das Schicksal der Unterlegenen}

Im Verlauf des Winters nach der Maxener Kapitulation wurden die gefangenen preußischen Soldaten (neun Generäle, 500 Offiziere und etwa 12.500 Unteroffiziere und Mannschaften) an verschiedene Orte auf österreichischem beziehungsweise ungarischem Territorium verbracht. Nachdem die Offiziere nach den Gepflogenheiten der Zeit zunächst in Dresden bei würdigen, freundlichen Bürgern einquartiert worden waren, folgte im Dezember der Abmarsch in ein ganz fremdes, abergläubisches Land.89 Die Mannschaften hatte man bis dahin in der Umgebung von Dresden untergebracht - etwa auf der Burg Stolpen, wo sie wie die Schafe in den Hürden eingesperrt waren. Als Stationen der folgenden Märsche sind unter anderem die Städte Kolin, Brünn, Wiener Neustadt und Krems, beziehungsweise Rumburg, Budweis, Tulln, Bruck an der Mur und Völkermarkt bei Klagenfurth überliefert. Dort erfolgte die Einquartierung des Regiments. Unterwegs scheint es anfangs häufig zu Spannungen mit den Einwohnern der Städte, in denen die Truppen Quartier nehmen sollten, gekommen zu sein. Allerdings erwiesen sich die länger einquartierten Soldaten auch als erheblicher „Wirtschaftsfaktor", sodass man sie letztendlich doch beherbergte. Dies lässt darauf schließen, dass die Kriegsgefangenen - je nach Status - auch regere Kontakte zur Bevölkerung unterhielten..$^{00}$

Der Musketier Dominicus traf indessen am 22. Februar 1760 in seinem einstweiligen Quartier in Völkermarkt ein. Nebenbei bemerkt geben seine Aufzeichnungen ein beredtes Zeugnis davon, wie ein einfacher Soldat in einer Zeit, in der das Reisen nur wenigen Privilegierten vorbehalten war, die kulturellen und landschaftlichen Besonderheiten einer fremden Umgebung aufnahm. ${ }^{91}$ Während des

89 Aus den Aufzeichnungen des preußischen Leutnants von Hülsen, zitiert nach: HelEnE von HüLsen (Hg.), Unter Friedrich dem Großen. Aus den Memoiren des Aeltervaters 1752-1773, Berlin 1890, S. 106 f. Die Offiziere bewahrten sich auch in der Gefangenschaft gewisse Privilegien. Diese betrafen etwa die Qualität der Unterkunft, die Intensität der Bewachung, die Bewegungsfreiheit sowie das Behalten von Seitenwaffen, Degen beziehungsweise Säbel sowie des persönlichen Pferdes; VoIGTLÄNDER, Die preußischen Kriegsgefangenen (wie Anm. 49), S. 219 f.; Generalstab, Minden und Maxen (wie Anm. 3), S. 210.

90 Stephanie Schwarzer, Zwischen Anspruch und Wirklichkeit. Die Ästhetisierung kriegerischer Ereignisse in der Frühen Neuzeit (Forum Kulturwissenschaften 5), München 2006, S. $172 \mathrm{f}$.

91 Bernhard R. Kroener stellt heraus, dass das Militär „schon in der Frühneuzeit diejenige Großgruppe war, die sich am meisten im Raum bewegte und somit auch die meisten kulturellen Raumerfahrungen machte.“; Wencke Meteling, Perspektiven der Militärgeschichte. Raum, Gewalt und Repräsentation in historischer Forschung und Bildung, Potsdam, 17. bis 20. September 2007, in: Militärgeschichtliche Zeitschrift 67 (2008), H. 1, S. 172. Zur geografischen Mobilität im 18. Jahrhundert exemplarisch: WALTER Demel, Europäische Geschichte des 18. Jahrhunderts. Ständische Gesellschaft und europäisches Mächtesystem im beschleunigten Wandel (1689/1700-1789/1800), Stuttgart 2000, S. 65-70. Zum soldatischen Dasein als „Abenteuer" und Flucht aus der „engen Heimat“: Karl J. Mayer, Napoleons Soldaten. Alltag in der Grande Armée (Geschichte erzählt 12), Darmstadt 2008, S. 66-69. 
Marsches wurden die Soldaten meist von leichten Truppen (Croaten) bewacht und in den Quartieren zuweilen auch eingesperrt. Mehrere von Dominicus' Kameraden erfroren während der anstrengenden Märsche. Die Qualität der Unterkünfte variierte stark: Dominicus berichtet unter anderem von Massenunterkünften und dunstigen Löchern, in denen sich Krankheiten wie etwa die Ruhr schnell ausbreiteten. Viele Soldaten verstarben daher während der Gefangenschaft. Während ihrer Odyssee wurde den preußischen Soldaten mehrfach der Übertritt in österreichische Dienste angeboten. Auch diejenigen, die bereits in Diensten der Alliierten Österreichs gestanden hatten, erhielten bei völligem Pardon Gelegenheit zur Rückkehr. Mit Handgeld, freier Wobnung in Siebenbürgen und Beförderungen wurde dieser Übertritt zusätzlich schmackhaft gemacht. Von derartigen Angeboten machten die Soldaten mit zunehmender Dauer der Haft auch häufiger Gebrauch. Es wird von Fällen berichtet, in denen „Gemeine“ mit dem Wechsel des Dienstherrn auch zum katholischen Glauben übertraten. Die mit der Gefangenschaft verbundene Beschäftigungslosigkeit wirkte sich oftmals negativ auf die Disziplin aus. Gerade unter den Offizieren, die in der Gefangenschaft größere Freiheiten besaßen, kam es vermehrt zu „Exzessen“ und „Händeln“ etwa infolge von Trinkgelagen. Während die meisten einfachen Soldaten ihre Heimat erst nach dem offiziellen Ende des Krieges im Jahre 1763 wiedersehen sollten, vermochten sich einzelne Offiziere durch eigene Mittel oder Zuwendungen vermögender und einflussreicher Familienmitglieder selbst zu ranzionieren (auszuwechseln oder loszukaufen), sobald Maria Theresia einen Gefangenenaustausch gestattete. Dies erlaubte auch dem Leutnant Hülsen im Dezember 1761 nach zweijähriger Gefangenschaft die Rückkehr und die weitere aktive Teilnahme am Krieg. ${ }^{92}$

92 Den Aufzeichnungen Hülsens zufolge erbat die Stadt Wiener Neustadt von Maria Theresia sogar eine Verlängerung des Aufenthaltes der preußischen Truppen. Der Marsch der Gefangenen erfolgte in einzelnen Kolonnen, deren Zusammensetzung sich an der taktischen Gliederung orientierte. Gemäß dem Kartell von Grotkau hatte die Gewahrsamsmacht, also in diesem Falle Österreich, für den Unterhalt (auch die Besoldung) der Gefangenen zu sorgen. Da sich bei Maxen ein geschlossener Verband in die Hände des Gegners begab, ist davon auszugehen, dass diese Truppen auch die überlassene „Bagage“ mit sich führten. Die Kolonnen wurden also von einem umfangreichen Tross begleitet. Auch erwähnt Dominicus Weiber, die sich bei den Soldaten befanden. Für die Durchführung des Marsches waren „Marschkommissare“ (beispielsweise Landräte) verantwortlich, die sich wiederum mit den lokalen Behörden und Grundherren über die exakte Route und die Einquartierungen zu verständigen hatten. In den Quartieren mussten die Gefangenen ihre Verpflegung käuflich erwerben. Städte wurden als Marschstationen bevorzugt, da sie oft umfriedet und die Gefangenen somit leichter zu bewachen waren. Die Desertion aus der Gefangenschaft wurde mit harten körperlichen Strafen (Stockschlägen) belegt. Dominicus berichtet, dass von den 772 Mann, mit denen sein Regiment in Völkermarkt eintraf, bis zum Mai 1761176 Mann gestorben und 133 in fremde Dienste getreten sind. Überliefert ist auch der Suizidversuch eines preußischen Korporals nach dessen Übertritt in österreichische Dienste.LeutnantHülsenberichtet, dassaufgrund derallgemeinenBeschäftigungslosigkeit der Offiziere in Krems sogar ein Orden gestiftet wurde, der zur Verbreitung der Mäßigkeit dienen sollte. Für die Rückkehr der „Ranzionierten“ (im Falle des Leutnants Hülsen organisierte sein Onkel, Generalleutnant Hülsen, die Auslösung) wurde ihnen 
Obwohl den sächsischen Truppen nach der Kapitulation bei Pirna nicht der erhoffte Status von Kriegsgefangenen zuerkannt wurde, weist ihr weiteres Schicksal doch einige Parallelen auf. Der signifikante Unterschied besteht jedoch darin, dass die Mannschaften und Unteroffiziere zur Ablegung des preußischen Eides gezwungen und somit in das preußische Heer zwangsinkorporiert wurden. Die Ursachen für den zunächst einigermaßen reibungslosen Übertritt der sächsischen Soldaten lagen aber nicht nur in der Androhung von Gewalt. Die preußische Seite zog buchstäblich alle Register, um ihren „neuen“ Soldaten den Übergang erträglich zu gestalten: Handgeld, gute Verpflegung, Beförderungen und die Zusicherung, auch in Zukunft innerhalb der bisherigen Regimentsstrukturen - obgleich unter neuem Namen - auf heimatlichem Boden eingesetzt zu werden, verfehlten in einer solchen Ausnahmesituation beziehungsweise Grenzerfahrung ihre Wirkung vorerst nicht. ${ }^{93}$ In den folgenden Wochen marschierten die ehemals sächsischen Truppen unter anfangs eher nachlässiger Bewachung in ihre Winterquartiere, die teilweise auf sächsischem, aber auch auf preußischem Territorium lagen. Dabei wurden sie nach preußischem Muster ausgerüstet und ausgebildet. Offenbar verfuhr man dabei besonders hart, denn sächsische Deserteure gaben später zu Protokoll, dass sie von preußischen Offizieren als sächsische Hunde bezeichnet und oftmals sehr scharf tractiret worden wären. ${ }^{94}$

Das sächsische Offizierkorps ereilte währenddessen ein anderes Schicksal als die preußischen Offiziere bei Maxen. Während die "Gemeinen“ neu vereidigt wurden, entließ Friedrich II. die sächsischen Offiziere den Gepflogenheiten der Zeit entsprechend auf Ehrenwort oder „Parole“. Hierzu hatten die Offiziere später auch die Generäle - einen „Revers“ zu unterzeichnen. In der Folgezeit mussten sie sich an festgelegten Orten einfinden, wo sie für die Dauer des Krieges zu verbleiben hatten. ${ }^{95}$ Friedrich II. bot ihnen jedoch auch den Übertritt in preu-

ein „Ranzionspass“ ausgestellt; KerLer, Tagebuch des Musketiers Dominicus (wie Anm. 44), S. 78-90; von HüLsen, Unter Friedrich dem Großen (wie Anm. 89), S. 106116; Volgtländer, Die preußischen Kriegsgefangenen (wie Anm. 49), S. 12, 55-61; Brabant, Kesselsdorf und Maxen (wie Anm. 3), S. 193.

93 Zu den „Extremsituationen“ im Kabinettskrieg: ScHwarzer, Zwischen Anspruch und Wirklichkeit (wie Anm. 90), S. 198.

94 Insgesamt wurden aus den Gefangenen zehn neue preußische Infanterieregimenter errichtet. Besonderen Widerstand bei der Übernahme leisteten vor allem die sächsischen Garderegimenter, die zum Teil erst nach einigen Wochen vereidigt werden konnten. Einige sächsische Formationen (vor allem die Kavallerieregimenter) wurden aufgelöst und unter die preußischen Truppen verteilt. Näheres hierzu bei: von SALIsch, Treue Deserteure (wie Anm. 1), S. 133-143, 306-308.

95 Ein solches Angebot war für die Unteroffiziere und Mannschaften nicht möglich, da diese im zeitgenössischen Verständnis keine „Ehre“ besaßen (mit dieser Thematik setzten sich vor allem die „Militäraufklärer“ im späteren 18. Jahrhundert auseinander). Der „Revers“ legte den zukünftigen Aufenthaltsort der Offiziere fest und verbot ihnen bei Lebensstrafe jeden Fluchtversuch. Ein in Gefangenschaft geratener Offizier war damit für seinen Kriegsherrn bis zum Friedensschluss oder zur Auswechslung „tot“, auch wenn sich der Aufenthaltsort in dessen Herrschaftsgebiet befand. Die von den sächsischen Offizieren unterzeichnete Erklärung lautete: Ich engagire mich hiermit auf 
Bische Dienste an. Von diesem Angebot, was zumeist mit einer Beförderung einherging, machten nur wenige und vor allem jüngere sächsische Offiziere Gebrauch. Einer von ihnen, Carl Friedrich von Wolfersdorf, geriet später bei Maxen in österreichische Gefangenschaft. ${ }^{96}$ Indessen kam es bereits wenige Wochen nach der Kapitulation zu einem Phänomen, welches für das weitere Schicksal der Offiziere von entscheidender Bedeutung sein sollte: Die ins preußische Heer gepressten Sachsen entflohen ihren neuen Fahnen. Ungewöhnlich dabei war weniger die Tatsache selbst, sondern der Umfang und die Motive der Desertion. Auch durch preußische Gegenmaßnahmen konnte die Situation nicht unter Kontrolle gebracht werden - noch im Frühjahr 1757, also vor Beginn des nächsten Feldzuges, liefen die ehemals sächsischen Soldaten fast bataillonsweise und meist unter Führung ihrer Unteroffiziere davon. Ähnliches geschah in den Gefechten des Jahres 1757. Ihre Ziele waren zumeist die Vorposten der österreichischen Armee beziehungsweise das Erreichen des polnischen Territoriums. Von dort aus traten die jewei-

das verbindlichste und anf meine Parole d'honneur, daß anf Ihro Königl. Maj. in Preußen allergnädigste Ordre ich mich allermabl wenn und wohin höchstdieselben es befehlen werden zu stellen, ins besondere aber mich in keinen andern Militair- und Civil-Dienste oder Negotiation sie habe Nabmen wie sie wolle, weder directement noch indirectement gebrauchen laßen, sondern mich viel mehr an dem mir angewiesenen Orte ruhig halten will, bis höchstgedachte Ibro Königl. Majestät in Preußen über mich anderweit allergnädiglich disponiren werden und will mich allemabl einstellen, wo ich bingefordert werde. Als Aufenthaltsorte wurden zunächst Eisleben, Lübben, Guben und Wittenberg festgelegt. Mit dieser Versetzung an die Peripherie Sachsens sollte der Kontakt der Offiziere zu ihren ehemaligen Regimentern unterbunden werden. Dem sächsischen General von Rochow, der sich später über die Bestimmungen hinsichtlich seines Aufenthaltsortes hinwegsetzte, wurde mit dem Galgen gedroht. Da man seiner nicht sofort habhaft werden konnte, wurde in Naumburg ein Bildnis von ihm an den Galgen angeschlagen; vON SALIsch, Treue Deserteure (wie Anm. 1), S. 174 f., 178-180; VOIGTLÄNDER, Die preußischen Kriegsgefangenen (wie Anm. 49), S. 219. Zur sächsischen Militäraufklärung siehe auch KroLL, Soldaten im 18. Jahrhundert (wie Anm. 1), S. 181-200; Marcus vON SALISCH, Anmerkungen zum Selbstbildnis kursächsischer Offiziere im 18. Jahrhundert im Spiegel von Beständen der Bleckwenn-Sammlung des Militärgeschichtlichen Forschungsamtes, in: NASG 80 (2009), S. 263-275; Ders., Das Beispiel Sachsen: Militärreformen in deutschen Mittelstaaten, in: Karl-Heinz Lutz/ Martin Rink/Marcus von Salisch (Hg.), Reform - Reorganisation - Transformation. Zum Wandel in deutschen Streitkräften von den preußischen Heeresreformen bis zur Transformation der Bundeswehr, München 2010, S. 96-99.

96 Es kam zum Übertritt von 34 bis 37 Offizieren und sechs bis zwölf Fähnrichen. Dies entsprach etwa neun Prozent des sächsischen Offizierkorps. 41 Offiziere und -anwärter erhielten in den ehemals sächsischen Formationen wieder eine Anstellung. Darunter befanden sich u. a. acht Hauptleute und 20 Premier- beziehungsweise SecondeLeutnante. Davon wurden u. a. 19 Leutnante zu Hauptleuten befördert. Wolfersdorf trat allerdings im Dienstgrad eines Oberstleutnants in preußische Dienste über. Dass auch sächsische „Ausländer“ dort durchaus Karrierechancen besaßen, sei durch Wolfersdorfs Aufstieg bis zum Generalleutnant und Chef des Infanterieregiments Nr. 9 belegt; von Salisch, Treue Deserteure (wie Anm. 1), S. 170-173; Heinrich A. VerLOHREN, Stammregister und Chronik der Kur- und Königlich-Sächsischen Armee von 1670 bis zum Beginn des Zwanzigsten Jahrhunderts, hrsg. von Max Barthold/Franz Verlohren, Leipzig 1910, S. 560. 
ligen Anführer mit den österreichischen Kommandeuren und dem in Warschau weilenden sächsischen Hof in Kontakt. Selbstbewusst füllten die Unteroffiziere die durch das Fehlen der Offiziere entstandenen Lücken. Das Selbstverständnis und der Erfolg ihres Handelns belegen nicht nur, dass der Unteroffizier des 18. Jahrhunderts durchaus zu höheren militärischen Führungsaufgaben befähigt war. Es deutet zudem darauf hin, dass auch der „Mittelbau“ der militärischen Hierarchie bereits so etwas wie ein „persönliches Treueverhältnis“ zum verehrten „Landesvater“ empfand - eine Eigenschaft, die gemeinhin nur dem Offizierkorps zugeschrieben wird. Die unerwartet große Anzahl der Fahnenflüchtigen - auf Seiten der Gegner Preußens „Revertenten“ genannt - veranlasste den sächsischen Hof zur insgeheimen Zusammenführung derselben mit dem Ziel ihrer anschließenden Verwendung im „ungetrennten Corps“. Die Organisation dieses hierarchisch gegliederten „Sammlungswerkes“ wurde mit dem russischen, österreichischen und französischen Hof abgestimmt. Durch die Bildung neuer militärischer Formationen aus den Flüchtlingen erwuchs zudem ein hoher Bedarf an Offizieren. Somit gab die Fahnenflucht der sächsischen Mannschaften auch einen wesentlichen Impuls für die Reaktivierung großer Teile des seit Pirna „ruhiggestellten“ sächsischen Offizierkorps. Um unter dem Nabmen unsers großen Monarchen die Treue und Eyfer zeigen zu können, meldeten sich viele Offiziere freiwillig. Ebenso wie die Mannschaften und Unteroffiziere dem unter Zwang abgeleisteten preußischen Eid ${ }^{97}$ offenbar nur eine geringe moralische Bedeutung beimaßen, fühlten sich viele sächsische Offiziere mit der Zeit auch nicht mehr an

97 Der bestehende Eid auf den sächsischen Kurfürsten war während der Zeremonie am Lilienstein von preußischer Seite nicht aufgehoben worden. Die sächsischen Soldaten wurden nach ihrer Ankunft beim „Sammlungswerk“ durch Auditeure erneut auf die sächsischen Kriegsartikel vereidigt. Später, als Österreich und Frankreich gemeinsam über das gesammelte sächsische Korps verfügten, wurden die Truppen in Wien nochmals auf den sächsischen Kurfürsten, die Kaiserin Maria Theresia und den König von Frankreich vereidigt. Bei dieser Zeremonie fanden sächsische Fahnen Verwendung. Anwesend waren offenbar neben dem sächsischen Bevollmächtigten auch Maria Theresia sowie der französische Botschafter (Herzog von Choiseul). Der Auditeur hob in seiner Ansprache hervor, dass die sächsischen Soldaten, in welchem Lande [sie] auch seyn werden, in dem Dienst unßers allergnädigsten Landes Herrn verbleiben würden. Das Streben der Soldaten sollte darauf gerichtet sein, eben den Rubm zu erwerben, den unsere Cameraden im verwichenen Feld-Zuge zu verdienen, das Glück gebabt haben. Damit verwies der Auditeur auf die vier sächsischen Kavallerieregimenter, die während der Belagerung von Pirna in Polen stationiert und bereits 1757 in österreichischen Sold übernommen worden waren. Sie hatten unter dem Kommando des Oberstleutnants von Benckendorf u. a. einen entscheidenden Anteil am österreichischen Sieg in der Schlacht bei Kolin 1757. Anrede des Königl. Pohln. und Chur Fürstl. Sächß. OberAuditeurs an die Sächß. Trouppen, Wien, 19. April 1758; Relation der am 18ten Juny 1757 zwischen der Römisch Kayserl. Königl. Ungarisch. und der Pr. Armee vorgefallenen Bataille; Bibliothek Militärgeschichtliches Forschungsamt, Handschriftensammlung, Sign.: Q 59778. Pro Memoria des Grafen Fleming, Wien, 17. März 1758; Österreichisches Staatsarchiv, Abt. Kriegsarchiv Wien (im Folgenden: ÖStA/KA), Alte Feldakten/Hofkriegsrat, Siebenjähriger Krieg, Kart. 665, 3/36 b. Externbrink, Friedrich der Große (wie Anm. 5), S. 221. 
den von ihnen unterzeichneten „Revers“ gebunden. Hierzu trug auch die Tatsache bei, dass die sächsischen Offiziere von preußischer Seite kaum Unterhalt erhielten. Für ihr Verhalten sind daher nicht ausschließlich patriotische, sondern auch wirtschaftliche Argumente anzuführen. Der sächsische Hof und die von ihm lancierte Propaganda bemühten sich, eventuelle Bedenken gegen den Bruch des Ehrenwortes zu zerstreuen. Die „Sammlung“ hatte zur Folge, dass Ende des Jahres 1757 bereits über 7.000 sächsische Soldaten auf österreichischem und ungarischem Territorium versammelt waren. Dort leisteten sie zumeist Garnisonsdienste ab. Das ungewohnte Klima, die Unterkunfts- und Versorgungsbedingungen sowie der eintönige Dienst führten auch in ihrem Falle zu Krankheiten und ähnlichen Verfallserscheinungen, wie sie aus den Berichten der preußischen Gefangenen überliefert sind. Erst 1758 konnten sich der sächsische, österreichische und französische Hof auf eine Verwendung des nun etwa 10.000 Mann starken Infanteriekorps als Auxiliartruppen in französischen Diensten einigen. Hierzu wurden sie in Wien ausgerüstet und marschierten anschließend auf den westdeutschen Kriegsschauplatz ab. ${ }^{98}$ Unter dem Kommando des Prinzen Xaver von Sachsen (1730-1806) beteiligten sie sich an den dortigen Gefechten und bildeten ab 1763 den Grundstock des neu aufzustellenden kursächsischen Heeres. ${ }^{99}$

An der Organisation der "Sammlung“ war auch Feldmarschall Rutowski-und damit sei übergeleitet zum Schicksal der beiden verantwortlichen Heerführer - im Hintergrund beteiligt. Er verblieb nach der Pirnaer Kapitulation in „Amt und Würden“, wenngleich ohne aktive Verwendung. Obwohl es während dieser Zeit nie zu einer eingehenderen offiziellen Untersuchung der Umstände der Waffen-

98 Die Gründe für die Fahnenflucht waren u. a. von preußischer Seite nicht eingelöste materielle Versprechungen sowie übermäßige Härte in der Ausbildung, eine anfangs zu nachlässige Bewachung, der bevorstehende Einsatz „außer Landes“, Einflüsse der Zivilbevölkerung und der antipreußischen Propaganda sowie das Vorbild bereits entflohener Kameraden. Die Preußen reagierten darauf beispielsweise mit verschärfter Bewachung, Entwaffnung der sächsischen Soldaten, Überwachung des Grenzgebietes zu Polen und Untermischung zuverlässiger preußischer Soldaten unter die „unsicheren“ sächsischen Formationen. Die „gesammelten“ sächsischen Soldaten wurden zunächst beispielsweise in Prag, Eger und Budin zusammenführt und später u. a. nach Krems, Ybbs, Pressburg sowie nach Esseg, Raab, Stuhlweißenburg und Eisenstadt verlegt. Während ihres dortigen Aufenthaltes gerieten die Soldaten offenbar etwas aus dem Interesse des Wiener Hofes, was sich an der stockenden Zahlung der Versorgungsgelder festmachen lässt. Hierunter litten die Ordnung und die Disziplin der sächsischen Truppen. Als ihr Rückmarsch ins Reich beschlossen war, wurde der Fürst von Liechtenstein angewiesen, das erforderliche Gewöhr bereit zu stellen. Daneben sollten die Truppen in Wien das noch benöthigte Seiten Gewebr, Lederwerck, und andere requisita ingleichen neue Fabnen empfangen. Pro Memoria des Grafen Fleming, Wien, 17. März 1758; ÖStA/KA, Alte Feldakten/Hofkriegsrat, Siebenjähriger Krieg, Kart. 665, 3/36b; Schreiben des Grafen Neipperg an Staatskanzler Kaunitz vom 26. März 1758; ebd., 3/35a. Siehe hierzu im Detail: von SAlisch, Treue Deserteure (wie Anm. 1), S. 140-156, 181-210.

99 Zum Einsatz der sächsischen Truppen unter dem Kommando von Prinz Xaver: Pelizaeus, Prinz Xaver als Soldat und Militärreformer (wie Anm. 1); Grosse, Prinz Xaver von Sachsen und das sächsische Korps bei der französischen Armee (wie Anm. 1); von Salisch, Treue Deserteure (wie Anm. 1), S. 210-243. 
streckung vom Oktober 1756 kam, hatte diese dennoch ein Nachspiel: Bereits unmittelbar nach der Kapitulation gingen der sächsische Hof und die höheren gesellschaftlichen Kreise mit der Generalität hart ins Gericht. Das Heer hätte mutig geführt - Wunder vollbracht; allein die zaudernden Generäle hätten den Erfolg des Unternehmens verhindert, wurde spekuliert. Worte wie Hochverrat machten schnell die Runde. Von seinem Generalstab im Stich gelassen, habe sich einzig der Kurfürst, in einer ihm würdigen Weise benommen, lautete etwa die Meinung des Kurprinzen Friedrich Christian (1722-1763). Zumindest vor ihm hatte die sächsische Generalität Rechenschaft abzulegen. Die dabei vorgebrachten Argumente bewertete der Kurprinz als schwach. Außerdem kam es zwischen Rutowski und dem Grafen Brühl in Warschau zu einem regen Briefwechsel. In Zeitungen wie dem „Altonaer Post-Reuter“ erschienen außerdem offizielle Stellungnahmen des sächsischen Kurfürsten zu den Ereignissen am Lilienstein, worin wiederum die Nachlässigkeit der Generalität angeprangert wurde. Die sehr auf ihre Ehre bedachten Generäle reagierten auf diese Anschuldigungen empört und die Debatte zog sich noch bis weit in das Jahr 1757 hin. Der Feldmarschall erbot sich, Ebre und conduite vor einem unpartheyischen Kriegs-Rechte zu retten. An Brühl schrieb er: Ich bekenne, dass die Vorwürfe [...] mir das Herz zerreißen. Wenn es etwas gäbe, was mich in meinem Unglück trösten könnte, so ist es die Ueberzeugung von der Unmöglichkeit, in der ich mich befunden, den Naturgesetzen, der Uebermacht und dem Hunger zu widersteben. Eine Möglichkeit zur öffentlichen Rechtfertigung hatte Rutowski nicht mehr - dies war vielleicht auch nicht gewollt. Während einige seiner Generäle in den kommenden Kriegsjahren im Dienste der Alliierten doch noch Ruhm erwarben, lebte er zurückgezogen auf den Besitzungen der Familie Vitzthum von Eckstädt bei Leipzig. Im Jahre 1763, als es galt, das Heer zu reorganisieren, legte er aus gesundheitlichen Gründen sein Amt nieder und verstarb ein Jahr später. ${ }^{100}$

Graf Lehndorff (1727-1811), der Kammerdiener der preußischen Königin, notierte im November 1759, wenige Tage nach der Katastrophe von Maxen, in sein Tagebuch: Es ist ein Ereignis, das obne Gleichen in der Geschichte dasteht; weder

100 Der Siebenjährige Krieg trug in hohem Maße zur Steigerung der Nachfrage nach Presseerzeugnissen bei. Für die Propaganda der Krieg führenden Mächte spielten Tageszeitungen eine entscheidende Rolle. Die Verbreitung der Anschuldigungen gegen die sächsische Generalität wurde zwar nach einiger Zeit vom sächsischen Hof unterbunden, eine offizielle Widerlegung beziehungsweise Gegendarstellung erfolgte jedoch nicht. Ebenso wurden anonyme Schriften, welche die Umstände der Pirnaer Kapitulation zum Inhalt hatten, wieder eingezogen. In der erhaltenen Korrespondenz der sächsischen Generalität wird Brühl häufig beschuldigt, den Kurfürsten gegen die Generäle aufgebracht zu haben, um von der eigenen Verantwortung für den desolaten Zustand der Armee abzulenken; von SAlisch, Treue Deserteure (wie Anm. 1), S. 35, 175-178; Agatha Koвuch, Zensur und Aufklärung in Kursachsen. Ideologische Strömungen und politische Meinungen zur Zeit der polnisch-sächsischen Union (16971763) (Schriftenreihe des Staatsarchivs Dresden 12), Weimar 1988, S. 153 f.; siehe hierzu auch: Holger Dainat, Der Siebenjährige Krieg in den Medien, in: „Krieg ist mein Lied“ (wie Anm. 62), S. 9-26. 
Blenheim, noch Pirna [!], noch Pultawa können damit verglichen werden. Demnach war die Kapitulation Finks aus preußischer Sicht nicht nur eine militärische Niederlage, sondern eine Zäsur von herausragender historischer Bedeutung. Und General Fink bekam dies zu spüren. Dass auch der erwähnte Leutnant Hülsen nach der Kapitulation von einem unerbörten Vorfall schrieb und sich mit seinen Kameraden unter den Rufen Adieu, honneur! Adieu fortune! angeblich weinend umarmte, geschah bereits in düsterer Vorahnung. Am 21. November 1759 hatte der preußische König im Zustand völliger Fassungslosigkeit den Vorfall als ein gantz unerbörtes Exempel bezeichnet. Wog aufgrund der vorangegangenen Kriegsereignisse allein der Verlust der Truppen (und etwa eines Zehntels des preußischen Offizierkorps) schon schwer genug, so bildete das "moralische Debakel“ gleichsam den „geistigen Tiefpunkt des Krieges". ${ }^{101}$ Nicht die militärische Niederlage war die einzige Katastrophe, sondern ihre Umstände und ihre Wirkung auf die Armee: An der Ehre, so soll der König erklärt haben, haben wir einen ungeheuren und unersetzlichen Verlust erlitten; Jabrbunderte sind nötig [...] ibn wieder zu tilgen. ${ }^{102}$ Dass man in der Umgebung des Königs aufgrund seiner kühnen Operationsplanung und mehrdeutigen Befehlsgebung aber auch über eine Mitschuld des Monarchen reflektierte, belegt die berühmt gewordene Äußerung des Prinzen Heinrich vom Sturz des Phaeton. ${ }^{103}$ Als General Finck 1763 aus der Kriegsgefangenschaft in Innsbruck nach Preußen zurückkehrte, wurde von Friedrich II. eine eingehende Untersuchung der Vorfälle von 1759 veranlasst. Hierbei wurde nicht nur das Betragen Fincks, sondern auch dasjenige der „Ausländer“ Rebentisch und Gersdorff 104 untersucht. Da insbesondere die moralische Wirkung der Niederlage im Zentrum der Überlegungen Friedrichs II. stand, wurde ein Exempel an der Generalität statuiert: Das Urteil für Fink lautete ein Jahr Arrest in der Festung Spandau und Ausschluss aus der Armee. Seine Unterführer, die Generäle Rebentisch (Kassation und ein Jahr Festungshaft) und Gersdorff (Kassation und zwei Jahre Festungshaft), wurden ebenfalls hart bestraft. Ausschlaggebend war letztendlich auch hier nicht die Niederlage an sich, sondern Finks fehlende Kraft zum eigenständigen Entschluss in einer Krisensituation, also die Tatsache, dass er mit seinem Korps nicht agiret hatte. Fink versuchte später, sich in einer Denkschrift zu rechtfertigen. Nach Verbüßung seiner Strafe trat er 1764 als General der Infanterie in dänische Dienste über und verstarb 1766 mit nur 47 Jahren. Sein Regiment war schon 1763 an General Wunsch, der aufgrund seines Versuches durchzubrechen von der Kritik des Königs ausgenommen war, übertragen worden. General Rebentisch trat in die portugiesische Armee ein. Auch die übrigen bei Maxen ein-

101 Lotz, Kriegsgerichtsprozesse (wie Anm. 3), S. 101.

102 Schüssler, Friedrich (wie Anm. 2), S. 397.

103 Schreiben an Amalie; zitiert nach Kunisch, Friedrich (wie Anm. 5), S. 239.

104 Otto Ernst von Gersdorff (1710-1773) trat 1726 in die kursächsische Armee ein, wechselte jedoch 1739 in preußische Dienste, wo er bis zum Generalmajor aufstieg. Bei Maxen kommandierte er einen fehlgeschlagenen Gegenangriff der Kavallerie; VerLOHREN, Stammregister (wie Anm. 96), S. 235 f. 
gesetzten Generäle wurden bestraft; viele Offiziere, die unter Fink gedient hatten, wurden spätestens 1763 im Zuge der Demobilmachung der Armee aus dem Dienst verabschiedet. Diese „Kollektivhaftung“ zeigt, dass der preußische König auch in späteren Jahren nicht von seiner Haltung zu den Maxener Ereignissen abwich. ${ }^{105}$ Friedrich II. zog 13 Jahre nach Kriegsende noch einmal Bilanz: 180.000 Menschen hatte Preußen nach seiner Rechnung im Siebenjährigen Krieg verloren, 16 Feldschlachten hatte der König gefochten; drei selbstständig operierende Korps waren vernichtet worden: ein Versorgungskonvoi bei Olmütz (1758), das Korps des Generals Fouqué bei Landeshut 1760 und eben das Korps Fink. Dies unterstreicht nochmals, wie exponiert und präsent die Schweinebunde von Maxen auch in der Erinnerung des alternden Königs geblieben sind. ${ }^{106}$

105 Die Anklageschrift hatte der preußische König selbst formuliert. Sechs Punkte davon betrafen General Fink. Sie gipfelten in der Frage, warum er sich mit dem ganzen Corps nicht bätte massacriren lassen? Obwohl durch das Gericht unter General Zieten die Entscheidungssituation Finks nicht in allen Anklagepunkten exakt rekonstruiert werden konnte (beispielsweise aus Unkenntnis des Geländes um Maxen oder aufgrund uneindeutiger Aussagen der vernommenen Zeugen), erfolgte die Verurteilung der drei Generäle. Friedrich II. bestätigte die Urteilsvorschläge am 26. Mai 1763 ohne Abänderungen. Wahrscheinlich noch im selben Jahre verfasste General Fink noch eine Rechtfertigungsschrift. Seine Darstellung der Ereignisse kontrastierte dabei stark von den Beurteilungen des Gerichtes. Fink betonte darin nochmals die Aussichtslosigkeit seiner Lage und seine Hoffnung, die Truppen durch baldigen Gefangenenaustausch erhalten zu können. Während seiner Haft, also in einer tiefen Lebenskrise, hat Fink dann seine „Gedanken über militärische Gegenstände“ niedergeschrieben, die durchaus humanaufgeklärte Züge tragen. Dies geschah offenbar nicht ohne Hoffnung, wieder in das preußische Heer aufgenommen zu werden. Ungeachtet aller Vorfälle wird Friedrich II. von Fink als größter König und größter General unserer Zeit beschrieben; Gedanken über militärische Gegenstände von dem ehemaligen Königlich Preußischen Generallieutenant, nachmaligen Königlich Dänischen General der Infanterie Friedrich August von Fink. Herausgegeben und mit Anmerkungen und Zusätzen versehen von $[\mathrm{M}]$ oritz [A]dolf von Winterfeld, Berlin 1788, in: Krise, Reformen - und Militär (wie Anm. 24), S. 249; zum Prozess gegen Fink im Detail: Lotz, Kriegsgerichtsprozesse (wie Anm. 3), S. 102-117; Winter, Die kriegsgerichtliche Untersuchung (wie Anm. 3), S. $150-169$.

106 Rückblick aus „Der Siebenjährige Krieg“, in: Friedrich der Große, Gedanken und Erinnerungen (wie Anm. 36), S. 63. General de la Motte Fouqué geriet mit seinen Korps ebenfalls in österreichische Gefangenschaft. Die preußischen Verluste beliefen sich auf etwa 8.000 Mann. Fouqué hatte - sicherlich die Ereignisse von Maxen vor Augen - seine Truppen bis zuletzt Widerstand leisten lassen. Trotz des wiederum empfindlichen Verlustes äußerte sich Friedrich II. später sehr lobend über Fouqué und verglich die Aufopferung des Korps mit der Verteidigung der Thermopylen durch den Spartanerkönig Leonidas 480 v. Chr. Der Überlieferung zufolge soll er bereits auf die ersten Nachrichten von der Niederlage Fouqués die Hoffnung geäußert haben, sein General habe sich wie ein braver Offizier zur Wehr gesetzt und nicht kapituliert, wie jene Schweinebunde bei Maxen. Fouqué kehrte nach dem Ende des Krieges nicht mehr in den Militärdienst zurück, sondern wirkte als Domherr zu Brandenburg; Kunisch, Friedrich (wie Anm. 5), S. 450; Duffy, Friedrich (wie Anm. 1), S. 228-231, 284 f.; von SAlisch, Treue Deserteure (wie Anm. 1), S. 251; Schüssler, Friedrich (wie Anm. 2), S. 488 f.; Der Siebenjährige Krieg 1756-1763. Landeshut und Liegnitz (Die Kriege Friedrichs des Großen 3/12), hrsg. vom Großen Generalstab, Kriegsgeschichtliche Abteilung II, Berlin 1913, S. $99-121$. 


\section{Zusammenfassung}

Pirna und Maxen waren trotz aller Dramatik „ruhige“, das heißt einigermaßen geordnet ablaufende Kapitulationen. Daher war das unmittelbare Risiko für die Kapitulanten zumindest im Moment der Waffenstreckung erheblich geringer als etwa in der Hitze eines laufenden Gefechtes. ${ }^{107}$ Die militärischen Operationen, welche für die jeweiligen Heere zur Situation der Kapitulation führten, waren indessen völlig verschieden. Zwar beruhten beide Kapitulationen auf einer grundlegenden Fehleinschätzung des Terrains und der Absicht des Gegners, auf Schwierigkeiten bei der Koordination des Entsatzes, auf einem letzten Entschluss, der nicht von den Feldherren allein, sondern auf breiterer Basis gefällt wurde, sowie auf falschen Hoffnungen bezüglich des weiteren Schicksals der kapitulierenden Truppen. Auch hinsichtlich der Zeremonie der Waffenstreckung ergeben sich interessante Parallelen. Aufgrund der förmlichen, andauernden „Blockierung“ entspricht die Lage bei Pirna allerdings viel eher einem zähen „Ringen zwischen der moralischen Kraft des einen und des andern".108 Auch können die Auswirkungen der Belagerung von Pirna auf den weiteren Verlauf des Siebenjährigen Krieges als schwerwiegender angesehen werden als die Folgen der Katastrophe von Maxen. Sicher wogen der dortige Verlust an Soldaten und das moralische Signal in diesem Stadium des Krieges schwer für Friedrich II. und seine Armee. Eine wesentliche Ursache, dass es überhaupt zu einem Kriegsjahr 1759 kam, ist indessen bereits im Herbst 1756 zu finden. Es gelang dem sächsischen Heer durch seinen unerwarteten Widerstand, die preußischen Pläne einer kurzen, durchschlagenden Kriegführung nachhaltig zu stören. Sicher ist es stets eine heikle Angelegenheit, im Nachhinein über Erfolg, Misserfolg und mögliche Handlungsoptionen militärischer Operationen urteilen zu wollen - dennoch seien hier einige Fragen erlaubt: Wie hätte sich das Kriegsgeschehen in den Jahren 1756/57 entwickelt, wenn Friedrich II. mit voller Kriegsmacht - vielleicht sogar verstärkt mit sächsischen Truppen - rasch gegen die unfertig gerüsteten Österreicher gezogen wäre? Wie hätte sich dann die noch ungefestigte antipreußische Koalition verhalten? Wäre es vielleicht nur zu einem ein- oder zweijährigen Dritten Schlesischen Krieg gekommen? Clausewitz fällte hierzu ein interessantes Urteil: Es ist nicht zu bezweifeln, dass Friedrich der Große, wenn die Sachsen, anstatt in ibr Lager von Pirna zu gehen, nach Böhmen gegangen wären, Österreicher und Sachsen in demselben Feldzuge bis über Prag hinausgetrieben und diesen Ort genommen haben würde. 109

Zudem ist die Geschichte der Kapitulationen von Maxen und Pirna sehr eng an zwei Personen geknüpft: Generalfeldmarschall Rutowski und Generalleutnant

\footnotetext{
107 Schwarzer, Zwischen Anspruch und Wirklichkeit (wie Anm. 90), S. 170; Keegan, Das Antlitz des Krieges (wie Anm. 46), S. 331.

108 Keegan, Das Antlitz des Krieges (wie Anm. 46), S. 353.

109 Clausewitz, Vom Kriege (wie Anm. 4), S. 553.
} 
Fink. Wie problematisch militärisches Handeln für den Oberkommandierenden im Felde sein konnte, wenn der eigentliche Kriegsherr in seinem distanzierten „Feldherr-im-Schloss-Dasein"110 kein ungetrübtes Bild von der Lage vor Ort hatte und durch die erforderlichen Rücksichtnahmen eher eine Belastung für das Heer darstellte, zeigt das Agieren Rutowskis. Die Nachwelt kannte dennoch wenig Rücksicht: Ungeachtet aller Menschlichkeit, die seiner Entscheidung am Lilienstein zugrunde lag, stellt er bis heute zumeist nicht mehr dar als einen unehelichen Sohn Augusts des Starken und den Verlierer von Kesselsdorf und Pirna. Dies wurde auch dadurch befördert, dass man von offizieller sächsischer Seite über die Pirnaer Ereignisse lange Zeit den „Mantel des Schweigens“ breitete und daher die Dokumentation vor allem durch die "Siegerperspektive“ der borussophilen Geschichtsschreibung erfolgte. ${ }^{111}$ Wie übermächtig, ja geradezu lähmend, sich andererseits die räumliche Nähe eines König-Feldherrn auswirken konnte, belegt das Beispiel Finks. Ähnlich aufgeklärt-human denkend wie Rutowski fand der General seine Grenzen nicht in der Heeresökonomie, sondern in der Person des Monarchen. Seine Waffenstreckung lag keineswegs außerhalb des militärisch Vorstellbaren - dennoch tat er etwas, was in den Augen des Königs nicht sein durfte. Vor der Geschichte blieb er meist nicht mehr als Fink, der Kapitulant von Maxen. Die zeitgenössische Propaganda hat ihn entsprechend wenig geschont, der „Finkenfang“ wurde zum Gegenstand zahlreicher polemischer Dichtungen und Lieder:

Wo ist der beste Herd zum Vogelfang in Sachsen?

Nicht weit von Falkenhayn, beim Rittergute Maxen. Auf einen Ruck fing Daun, wer sollte das wobl meinen, $J a$, es wird aller Welt ganz lügenhaft erscheinen, 1 Finck, 8 große Schnern und 18000 Meisen, Zum Braten tangen sie, der Teufel mag sie speisen!112

Ein fiktiver allerunterthänigster Rapport Fincks bringt die geografisch nahe beieinander liegenden Orte der beiden Kapitulationen in direkte inhaltliche Verbindung:

110 KeEgan, Das Antlitz des Krieges (wie Anm. 46), S. 394.

111 Bezeichnend hierfür ist etwa, dass Johann Gottlieb Tielke in seinen militärwissenschaftlichen Betrachtungen das Lager bei Pirna (das er als Kriegsteilnehmer selbst miterlebte) nie eingehender analysiert hat. Auch der erwähnte J. G. Hoyer veröffentlichte seine Betrachtungen zu Pirna erst 1809 (hierbei ist jedoch nicht eindeutig geklärt, ob es sich beim Verfasser um J. G. Hoyer (1762-1821, ab 1815 in preußischen Diensten) oder J. G. von Hoyer (1766-1812, immer in sächsischen Diensten) handelt); VERLOHREN, Stammregister (wie Anm. 96), S. 289.

112 Zitiert nach Brabant, Kesselsdorf und Maxen (wie Anm. 3), S. 209. Mit Schnern sind Schnarr- beziehungsweise Misteldrosseln gemeint. 


\section{O großer Friederich! Ich rückte mit den corps}

Von Langenkesselsdorf bis Dippoldiswalde vor.

$$
[\ldots]
$$

Man jagte uns davon, man trieb uns bis Maxen, Alldorten fing uns Daun, just so, wie du die Sachsen.

Dieses ist der rapport, o großer Friederich, Den ich erstatten soll; das Corps empfieblet sich. ${ }^{113}$

Der hier zuweilen nur skizzenhaft vorgenommene Vergleich vermag das Potenzial des „dritten Blickes“ moderner Militärgeschichtsschreibung (oder der „Militärgeschichte in der Erweiterung") nur anzudeuten. Weder die tradierte Perspektive einer Geschichte „von oben“( „Generalstabshistorie“) noch die in letzter Zeit oft bemühte Sichtweise „von unten“ vermögen Streitkräfte im Friedensalltag und im Kriegseinsatz umfassend zu dokumentieren (Wo muss beispielsweise ein Soldat innerhalb der militärischen Hierarchie stehen, um für die jeweilige Forschungsperspektive noch oder nicht mehr interessant zu sein? Wäre es wirklich gerechtfertigt, das enorme Potenzial detaillierter biografischer Studien etwa zu Fink oder Rutowski zu ignorieren, indem man sie einfach als angestaubte Geschichte „großer Männer“ abtut?). Nur eine Betrachtung „von der Seite“ 114 erscheint annähernd in der Lage, ganzheitlich darzustellen, wie sich eine Armee im Spannungsfeld von Kampf und Niederlage, Hoffnung, Ungewissheit und Enttäuschung, Kohäsion und Zerfall, von Hunger, Angst und Eingesperrtsein, von Ehrgefühl und Aussichtslosigkeit verhält - und zwar von der oft „schweigenden Masse“ der einfachen Soldaten bis hin zum Truppenführer, denn alle Glieder des Systems „Militär" bestimmen Binnenleben und Außenwirkung dieses Organismus auf ihre Weise. ${ }^{115}$

113 Zitiert nach ebd.

114 Dieser beachtenswerte Ansatz wurde während der 48. Internationalen Tagung für Militärgeschichte 2007 von Bernd Wegner (Hamburg) vorgeschlagen. Er fand bislang jedoch kaum Resonanz und Niederschlag im Tagungsbericht und -band; vgl. Meteling, Perspektiven der Militärgeschichte (wie Anm. 91), S. 166-180.

115 Im Hinblick auf die Ereignisse von Maxen und Pirna ist John Keegan nur zuzustimmen, wenn er - heute leider nur noch selten beachtet - bereits 1975 notierte: „Gemeinsam ist allen Schlachten [und eine Belagerung war im 18. Jahrhundert ein der Schlacht durchaus ebenbürtiges Mittel, Anm.] etwas Menschliches: das Verhalten von Menschen im Ringen um die Vereinbarkeit ihres Selbsterhaltungstriebes mit ihrem Ehrgefühl und der Erreichung eines Zieles, um dessentwillen andere Menschen zu töten bereit sind. So ist denn die Betrachtung der Schlacht immer eine Beschäftigung mit der Angst und gewöhnlich mit Mut, immer mit Führung und meist mit Gehorsam, immer mit Zwang und manchmal mit Auflehnung, immer mit Furcht und manchmal mit freudiger Erregung, immer mit Ungewissheit und Zweifel, Fehlinformation und Fehleinschätzung, meist mit Glauben und hin und wieder mit Vision, immer mit Gewalt, manchmal auch mit Grausamkeit, Selbstaufopferung und Mitleid; vor allem bedeutet sie stets ein Sichauseinander-Setzen mit Gemeinsamkeitsempfindungen und zumeist auch Zerfall.“; Keegan, Das Antlitz des Krieges (wie Anm. 46), S. 354. 